\title{
Monitoring and Identification of the Seismically Isolated "Our Lady of Tears" Shrine in Syracuse
}

\author{
Daniele Losanno, Mariacristina Spizzuoco \\ Department of Structures for Engineering and Architecture, Univesity of Napoli “Federico II”, Naples, Italy \\ Email:spizzuoc@unina.it
}

How to cite this paper: Losanno, D. and Spizzuoco, M. (2018) Monitoring and Identification of the Seismically Isolated "Our Lady of Tears" Shrine in Syracuse. Open Journal of Civil Engineering, 8, 373-410.

https://doi.org/10.4236/ojce.2018.84028

Received: February 26, 2018

Accepted: October 21, 2018

Published: October 24, 2018

Copyright $\odot 2018$ by authors and Scientific Research Publishing Inc. This work is licensed under the Creative Commons Attribution International License (CC BY 4.0).

http://creativecommons.org/licenses/by/4.0/

\begin{abstract}
This paper describes the installation and management of the monitoring system of the "Our Lady of Tears Shrine" in Syracuse, whose dome is an imposing r.c. and prestressed r.c. structure of about 22,000 ton that was seismically isolated by flat sliding devices with hysteretic dampers. The monitoring system, representing an upgrading and improvement of an old system never made working, has some innovative features, because it allows to manage with the same dedicated hardware and software both the slow (thermal variations, relative humidity, wind direction and velocity) and the fast acquisitions (dynamic vibrations by wind and earthquake). The monitoring system was inserted among those structures maintained and controlled by the Seismic Observatory of Structures of the National Department of Civil Protection. Some records of low magnitude earthquakes allowed to validate the correct behaviour of the whole structure, as well as to make a dynamic identification of the complex construction and to calibrate a detailed finite element model of the Sanctuary, thus predicting isolators' behaviour under design earthquake.
\end{abstract}

\section{Keywords}

Seismic Isolation, Structural Health Monitoring, Dynamic Identification,

FEM Model, Non Linear Analysis

\section{Introduction}

In the last decades, a lot of existing or new constructions located all over the world have been object of seismic isolation interventions, aiming to passively control their structural behaviour. The efficacy of such interventions has been tested during recent real ground motions, as well as within laboratory and in-situ testing campaigns. This technology is now recognized as allowing struc- 
tures to attain higher safety levels with respect to those achieved by conventional structures, even if modern seismic criteria are applied. Its large diffusion allows achieving a sensible reduction of seismic risk and is favoured by reliable codes and optimised computations [1]-[6].

On the other hand, the new monitoring technologies have now a fundamental role in the structural field and have been progressing by supporting and helping the research through the use of more and more accurate and cheap instrumentations and methodologies: the structural monitoring represents an increasingly accessible reality, so that it can be considered one of the most important mean of decision support [7] [8].

In its first applications, the need of a structural monitoring derived from the need to determine the safety conditions of historical constructions. At national level, during the last years of the twentieth century, the first case studies were relative to monumental buildings, as a consequence of a rediscovery of the Italian architectural heritage. Nowadays, the application field of the structural monitoring is extended to all the civil engineering constructions, from the transport infrastructures (bridges, dams, galleries, etc.) to the strategical buildings. Such a spread is due to multiple reasons: the technological progress in terms of sensors and data processing; the need to get more information on how a structure behaves, so reducing the uncertainties on its safety; the potentialities in the framework of the emergency management during catastrophic events; the local and/or global real-time control of the structure.

A structural monitoring system is able to acquire (in continuous, if necessary) the values assumed by some significant quantities, to warn appointed technicians on possible anomalies or the overcoming of defined threshold values, and the consequent automatic activation of alarm procedures and/or of suitable emergency measures. These technologies must allow to obtain all those information which points out a damage, an unexpected response or a change in the structural behaviour, and, if necessary, they must provide significant data concerning the environmental input. From the knowledge of these information derives the possibility to actuate eventual maintenance interventions, before the latters become very onerous in economic terms.

The static monitoring is addressed to observe the slowly variable quantities, as those related to thermal variations and meteorological phenomena: in spite of the greater simplicity with respect to the dynamic monitoring, it has huge potentialities, as happens when the data related to wind actions are acquired. The results of the static monitoring allow to the designer to get useful indications for a correct analysis of the structural behaviour.

The most important innovations have been achieved in the framework of the dynamic monitoring, directed to observe rapidly variable physical quantities. Such a kind of system can be designed in different ways, according to the desired objectives: the dynamic characterization of the monitored structure, the assessment of the time varying response of the structure, the transmission of a seismic 
excitation along a structure, etc.

Some years ago, the Italian National Seismic Service (SSN) started an important project, called Seismic Observatory of Structures (OSS), representing a complex network of structures properly selected on national scale, which include a continuous monitoring system able to provide useful experimental data and to transmit alarms in case of seismic events: bridges, public constructions as hospitals, city halls, churches, schools, isolated structures, etc. [9]. In the specific case of the isolated structures, the monitoring system allows to control the performance of the installed isolators. The OSS network is managed by a central computer, located in the SSN headquarters, where the recorded data flow in real-time: these data are automatically processed in a preliminary phase, and afterwards published on internet. Therefore, the OSS Project is able to provide to the academic and professional community all the data needed to evaluate the real response of a structure in exercise, to verify the performance of a control system installed on the monitored structure, etc. The goal of the OSS Project is that a monitoring system is able to return a picture of the structure, which is updated over time, and allows to determine an estimate of the resources needed to reduce the seismic risk. On the other hand, the OSS network provides the opportunity to compare the real constructions with the ideal project, whenever a check of the existing constructions' safety is required according to the new codes.

\section{Seismic Isolation of the Sanctuary's Dome}

\subsection{Description of the Structure}

The "Our Lady of Tears" Shrine (see Figure 1) is an imposing structure made up of r.c. and prestressed r.c. [10] [11], which was designed in Syracuse (Italy) by Prof. Riccardo Morandi. Over the foundations and the Crypt, the Upper Temple was erected toward the end of the Eighties. The upper structure is able to contain up to 11,000 people over an area of about $4000 \mathrm{~m}^{2}$. The Upper Temple is characterized by a huge dome having truncated-conical shape: according to radial symmetry, the dome consists in 22 sub-vertical ribs with a V-shaped cross-section whose arms have $20 \mathrm{~cm}$ thickness and variable length along the vertical development. The r.c. dome develops for $70.30 \mathrm{~m}$ from the top of 22 vertical columns rising from the Crypt's foundations, up to the top of the covering (Figure 2). The 22 ribs are horizontally connected through eight annular rings with a decreasing diameter along the height: the main prestressed concrete base ring immediately above the columns, an intermediate ring at elevation $16.10 \mathrm{~m}$ from the base of the dome, and other six rings placed at a constant distance of $8.40 \mathrm{~m}$ along vertical direction. Then, 19 external cantilevers depart from the main base ring: each of them represents the covering of a chapel, whose floor is suspended to the corresponding cantilever by means of eight steel tendons (Figure 3 ). The prestressed concrete base ring is able to absorb the horizontal thrust due to the dome's weight, and to counteract the torsional moments determined by the 


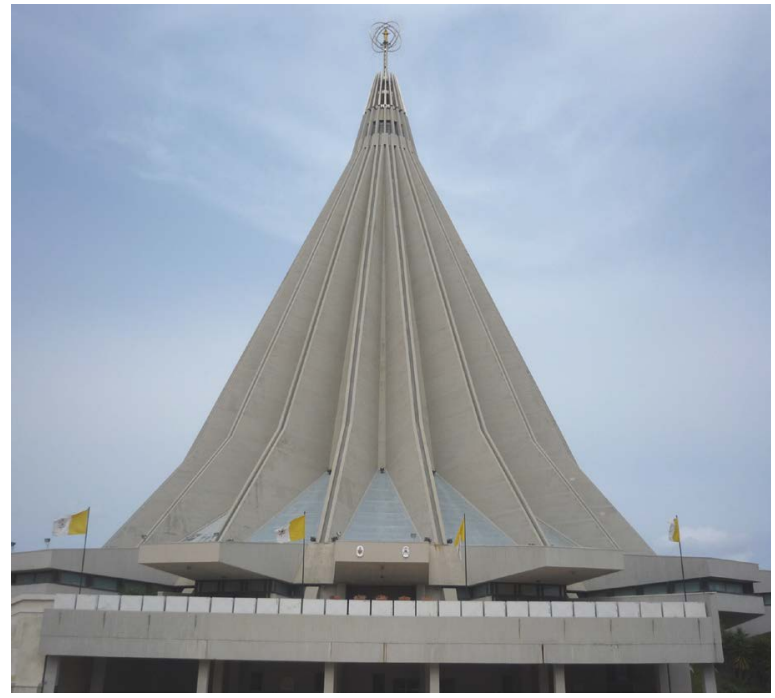

Figure 1. View of the Sanctuary.

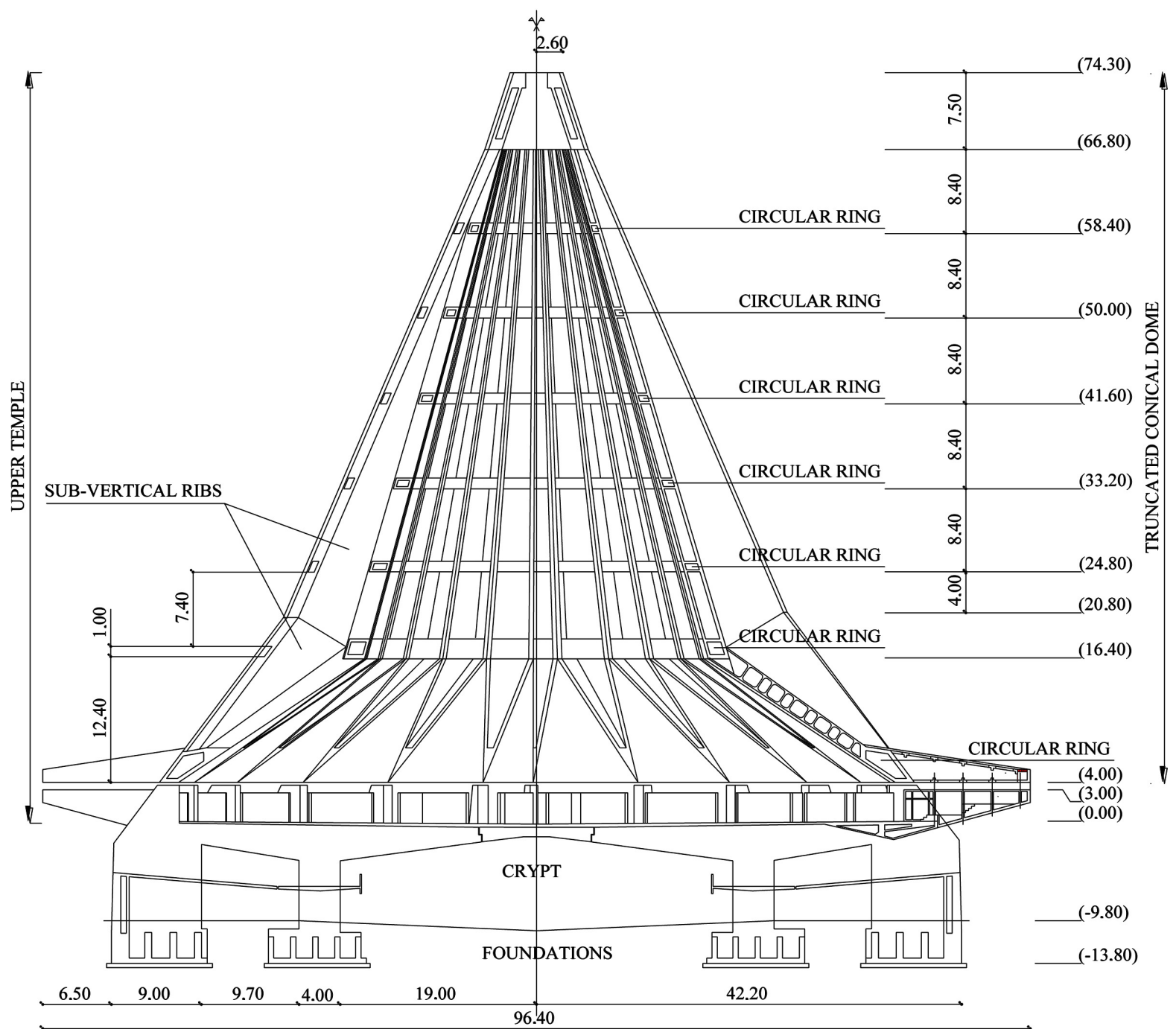

Figure 2. Vertical cross-section of the worship structure. 


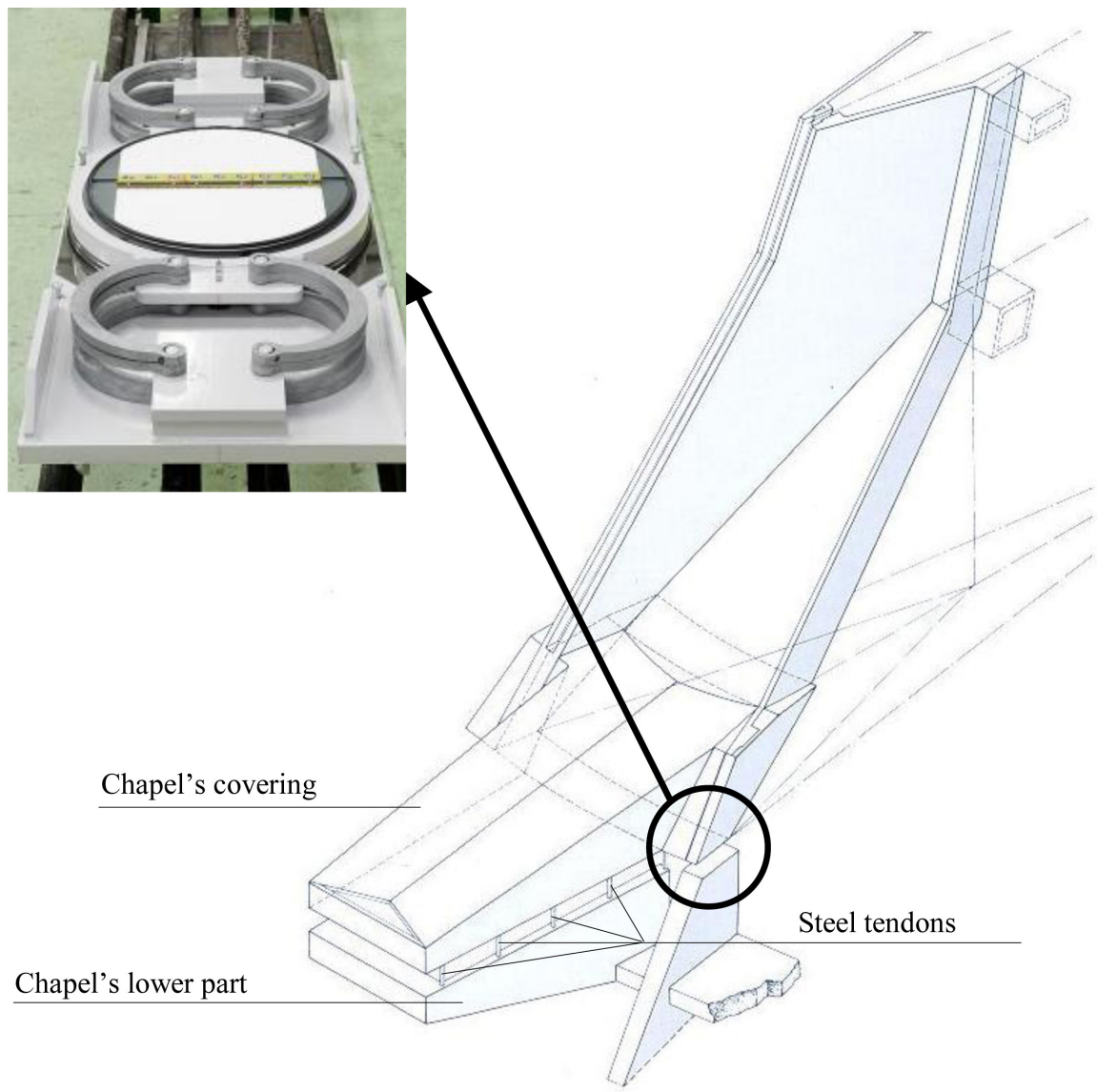

Figure 3. Isometric view of the lower part of one of 22 sub-vertical ribs of the Upper Temple and the corresponding isolator installed after the isolation intervention in 2005.

chapels. Up to the intermediate ring level, the plane zones bounded by the ribs are given by sub-horizontal r.c. slabs with variable thickness (Figure 4). At the highest part of each rib, their assembly forms a truncated cone that supports a bronze statue of Our Lady on the top. In the following, elevation $0.00 \mathrm{~m}$ is assumed at the extrados of the Crypt's covering. The base ring of the whole dome is supported on 22 r.c. columns: they have trapezoidal shape and are placed with $10.00 \mathrm{~m}$ spacing along the circle with a height of $3.74 \mathrm{~m}$ from the elevation $0.00 \mathrm{~m}$ of the Crypt's extrados (Figure 5). A steel-teflon sliding pot bearing with capacity $9810 \mathrm{kN}$ was installed between each column and the base ring above. The bearings allowed the displacements in the radial direction due to tensional and thermal variations, as well as the base ring's rotations, while the displacements in the tangential direction were restrained.

\subsection{Seismic Isolation of the Sanctuary's Dome}

The structural design was developed according to the Italian seismic code operative at the time of its construction. When the Italian seismic code of March 2003 [12] and the modifications and corrections of May 2005 [13] entered into force, the hazard level of the area including the city of Syracuse remarkably increased. 


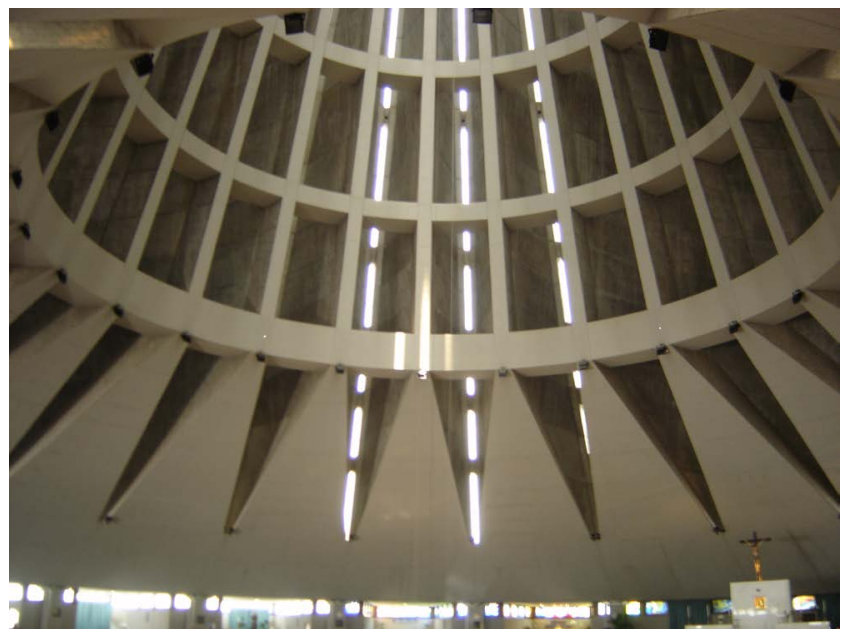

Figure 4. Internal view of the circular rings and the sub-horizontal r.c. slabs.

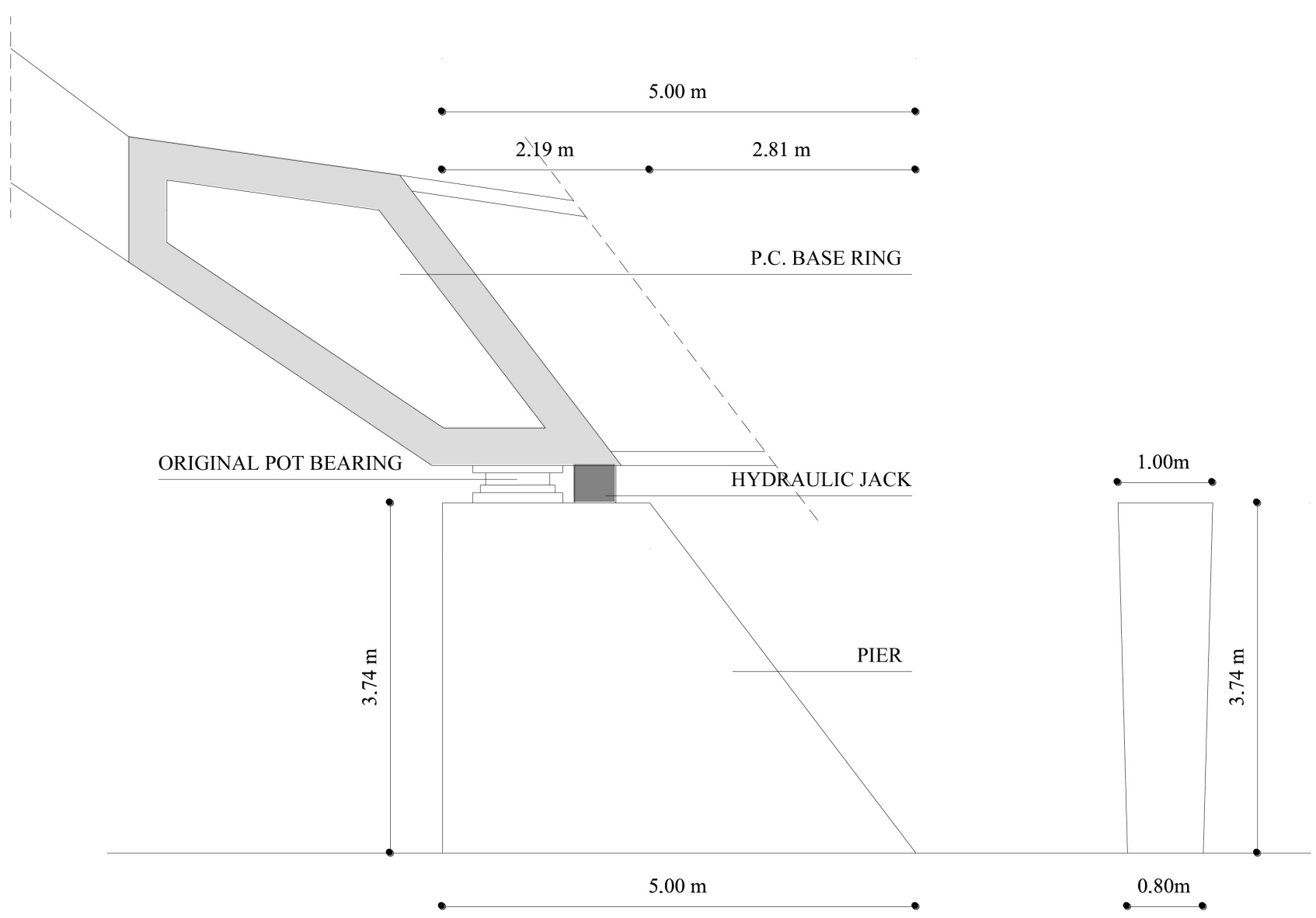

Figure 5. Vertical and transversal cross-sections of one column.

Some considerations were drawn from preliminary numerical analyses: a design earthquake could have caused a severe damage at the base of the columns, thus compromising the safety of the dome. On the other hand, an unexpected leakage of rubber from the 22 original bearings made necessary to substitute them through new devices. Therefore, in the period February-March 2006 the dome 
was seismically isolated from the structure below [14], by replacing the original bearings with new sliding isolators, equipped with dissipative elements made of steel (Figure 3). The retrofit intervention implied a new static scheme of the dome that allowed only the radial displacements caused by thermal variations, while making possible tangential displacements controlled by the elasto-plastic dissipative behaviour of the steel elements under severe earthquakes. The first attempt to make the above substitution one bearing at a time, by locally raising the imposing dome by means of hydraulic jacks installed at the bearing position, induced excessive stresses in the prestressed concrete base ring; the second attempt to raise the whole dome by simultaneously activating 44 jacks produced a cracking state because the position of the jacks was too eccentric with respect to the bearings; the third and final attempt made possible to raise the whole dome by the simultaneous operation of 114 jacks. The weight of the dome measured during the raising phase come out to be about $227,800 \mathrm{kN}$, and, after the bearings' substitution, while the lowering of the dome by simultaneous unloading of all the jacks [15] [16] permitted to estimate the vertical stiffness of the new devices.

\section{Continuous Monitoring of the Sanctuary}

\subsection{Why a Structural Monitoring System?}

One year before the end of the construction (in 1994), the Acceptance Committee required the installation of a properly designed structural monitoring system of the Sanctuary, because the bearing devices needed an accurate check: their inadequate operation could have caused a variation of the overall structural scheme together with the rise of unexpected stresses, thus compromising the structural reliability and the public safety. Besides, it was considered necessary to monitor the structural response to seismic inputs, being the Sanctuary was located in one of the Italian zones with highest seismic risk.

The acceptance test of the monitoring system was begun in June 1998, but it never started. Only after the execution of the seismic isolation intervention of the dome, the monitoring system was really activated through a maintenance and updating intervention. The new updated monitoring system is devoted to control the structural behaviour and the new antiseismic bearings, under the action of environmental loadings and seismic excitation. The "Our Lady of Tears Shrine" was then included in the constructions' network monitored within the OSS project [17].

\subsection{The Monitoring System Installed on the Structure}

After the seismic retrofit intervention, the updating of the monitoring system of the Sanctuary was redefined in order to allow the integrated and simultaneous management of the static, dynamic and metheorological channels; the acquired data are stored in three proper directories according to the kind of acquisition strategy, and transferred by a remote access to FTP areas and e-mail addresses. 
The new system provides the monitoring of the following quantities (Figure 6):

- radial and tangential relative displacements (Figure 7) by 4 of the 22 bearings (3), (9), (14) and (20);

- radial and tangential accelerations at 14 points (correspondent to 25 acquisition channels) at the elevation $-10.80 \mathrm{~m}$ of the Crypt plane (by the altar-Figure 8(a) - and the columns (4), (12) and (19) along radial direction), at the top of the previous three columns and at the intrados of the base annular

(a)

(b)
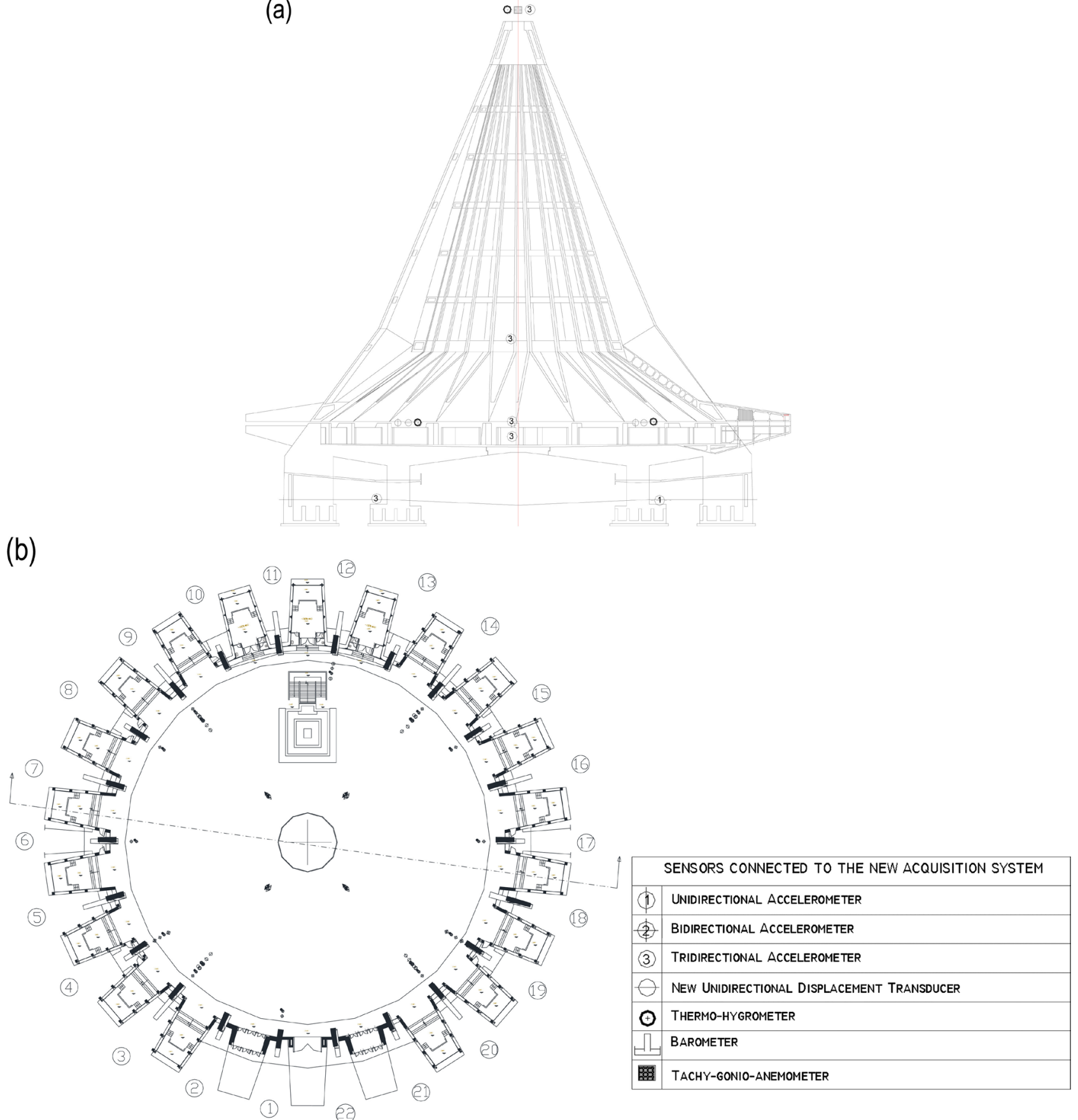

Figure 6. (a) Vertical cross-section of the monitoring system and (b) plan at elevation $4.00 \mathrm{~m}$. 


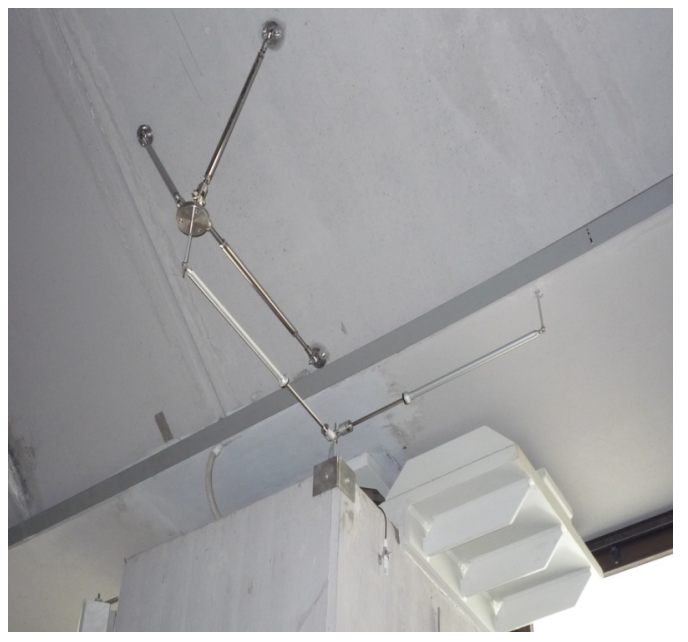

Figure 7. Displacement transducer (radial and tangential).

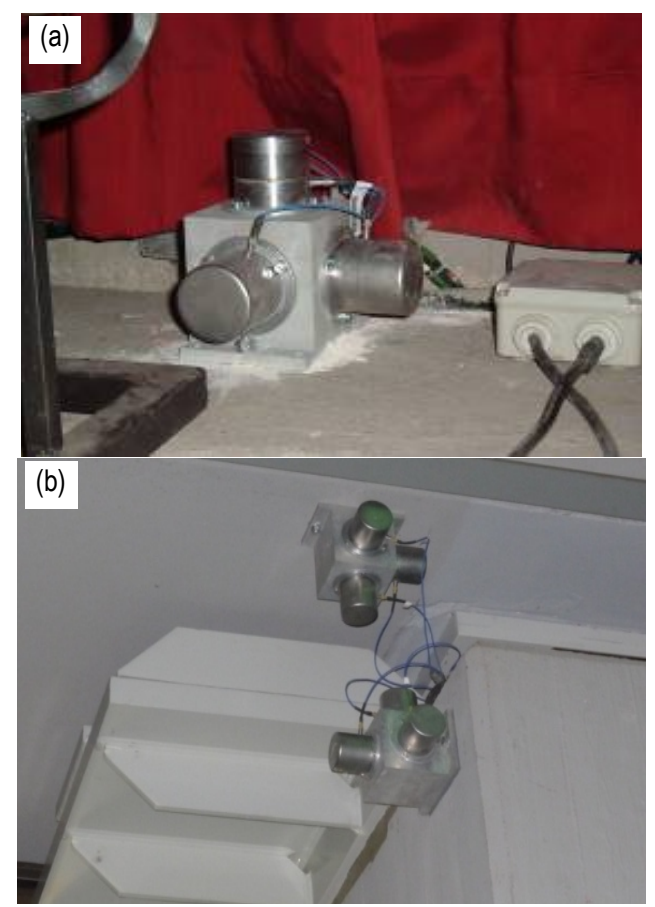

Figure 8. Tridirectional accelerometers in Crypt (a), at the isolator (b).

beam (Figure $8(\mathrm{~b})$ ) at elevation $+4.00 \mathrm{~m}$, at the intermediate annular beam $(+16.40 \mathrm{~m})$ by the same columns (4), (12) and (19), and finally at the structure's top in correspondence of column (12);

- vertical accelerations at 5 points distributed among the Crypt's altar, the top of column (12), the intrados of the base annular beam (Figure 8(b)), the intermediate ring-shaped beam by column (12), and the top of the dome by column (12);

- temperature and relative humidity inside the Upper Church (Figure 9) by four columns (3), (9), (14) and (20) placed at the four cardinal points, and outside the structure at the top; 
- wind velocity and direction at the top of the structure (Figure 10);

- atmospheric pressure at the elevation of the Crypt.

The sensors for the continuous monitoring system are: 30 accelerometers, 8 horizontal relative displacement transducers installed in couples on four bearings, 5 thermo-hygrometers measuring temperature and relative humidity, 1 barometer and 1 tachy-gonio-anemometer to measure wind's velocity and direction. The bidirectional and tridirectional accelerometers correspond to groups of, respectively, two or three unidirectional accelerometers mounted on the orthogonal faces of steel cubes: their measurement range is $\pm 2.5 \mathrm{~g}$ with a sensitivity of $1000 \mathrm{mV} / \mathrm{g}$, in each direction. The magnetostrictive linear position transducers have a measurement interval of $\pm 200 \mathrm{~mm}$ in both radial and tangential directions, i.e. compliant with the limit isolators' displacement $( \pm 200 \mathrm{~mm}$ for radial direction and $\pm 150 \mathrm{~mm}$ for tangential direction). The measurement range of the thermoigrometric sensors is $-40^{\circ} \mathrm{C}-+70^{\circ} \mathrm{C}$ for temperature and $0 \%-100 \%$ for humidity. The atmospheric pressure sensor is able to measure the atmospheric

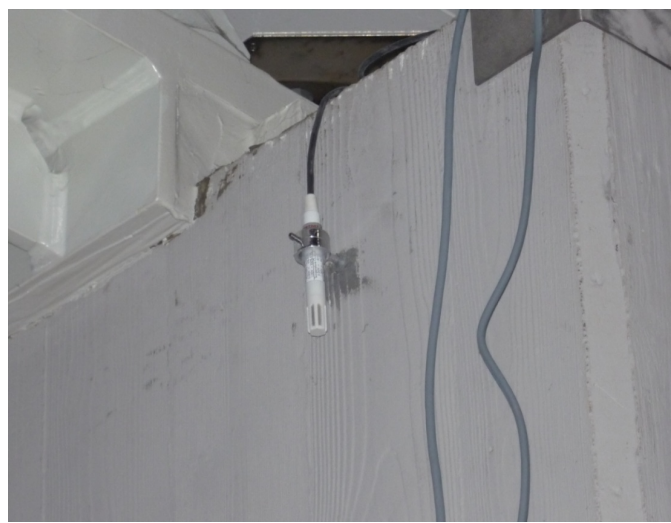

Figure 9. Thermoigrometer.

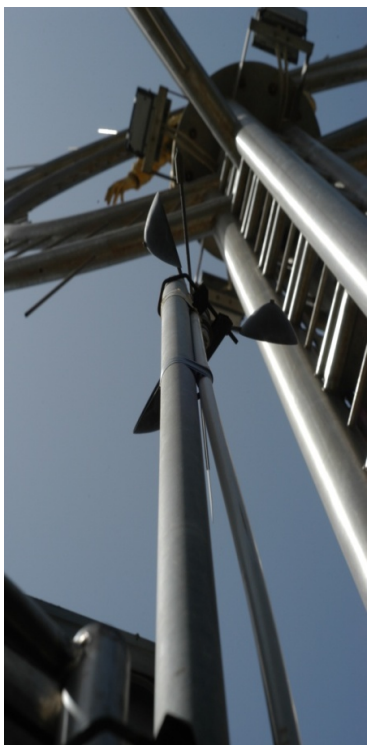

Figure 10. Tachy-gonio-anemometer. 
pressure in the range $800-1100$ mbar. All the acquired data are adequately processes from a properly programmed software, by using the code Labview (Vibrotest).

\subsection{Monitoring System's Architecture}

The architecture of the monitoring system singles out the following five sub-systems (Figure 11):

1) Power supply system for sensors.

2) Digital acquisition system.

3) Data management and storage system.

4) Remote management system.

5) System for management of power supply to peripheral devices and back-up module.

The power supply (sub-system 1) for sensors consists in two units: that one for dynamic transducers has two conditioners, each for 16 channels; that one for static sensors is able to supply 24 measurement transducers.

Two acquisition boards (DAQ—sub-system 2), each having 32 channels, represent the digital dynamic acquisition system. They acquire all the data corresponding to the measured physical quantities with a sampling frequency and an

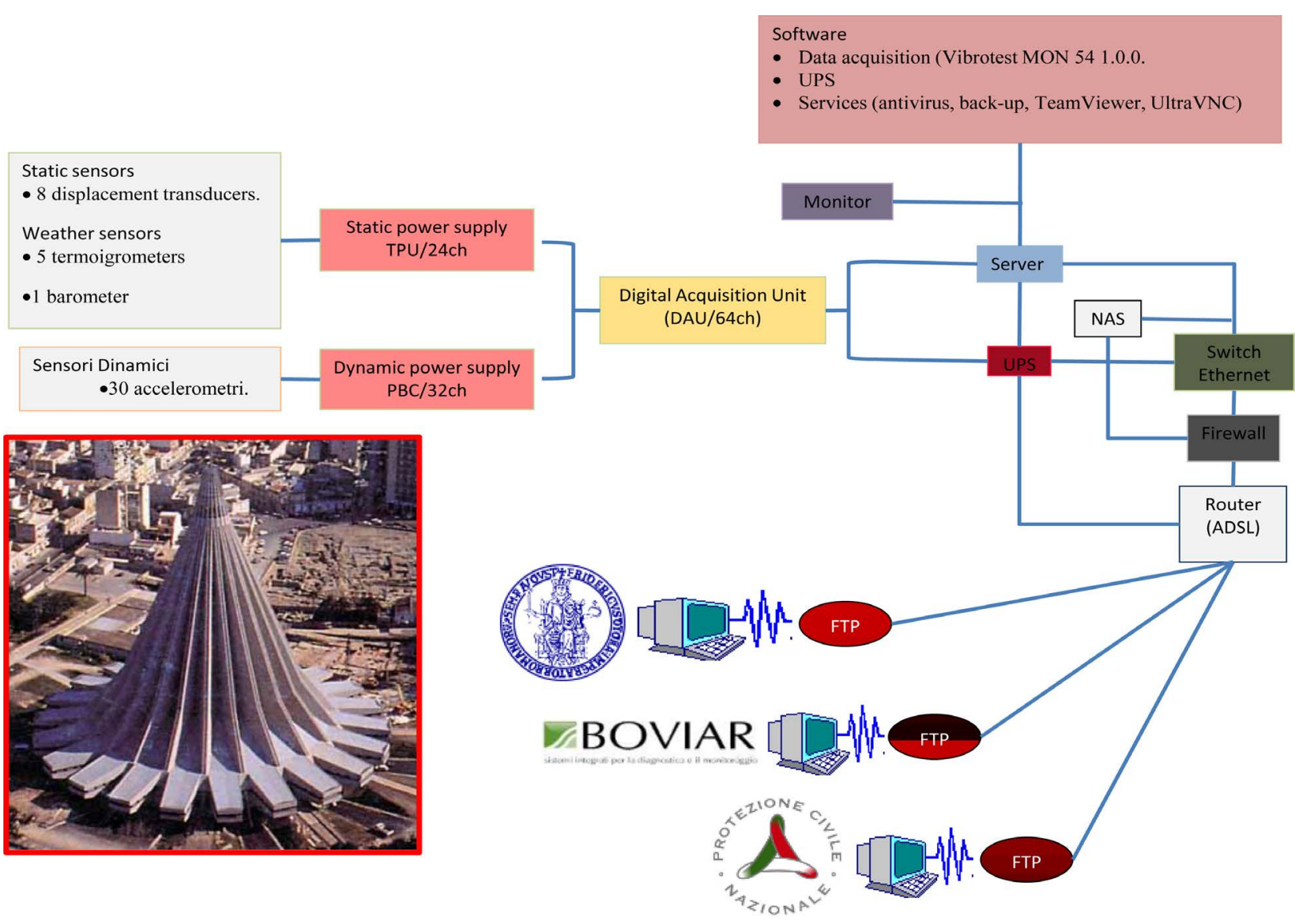

Figure 11. Monitoring system's architecture. 
acquisition strategy can be properly set.

The system for management and storage of the data (sub-system 3) has three components: $i$ ) a HP server, equipped with Vibrotest software, for the configuration and the data logging of recorded data; ii) a Network Attached Storage (NAS) unit for back-up of data; iii) a dedicated software for antivirus protection and back-up of data.

An ADSL router and a firewall for accesses protection are also included (sub-system 4). This system is able to automatically transfer the data and transmit alarms via e-mail and, in case, by SMS to dedicated FTP areas defined by the Italian Department of Civil Protection, the Department of Structures for Engineering \& Architecture of the University of Napoli Federico II, and the company Boviar Srl.

The System includes a Uninterruptible Power System (UPS—sub-system 5), that is able to provide electrical energy to the system, with an autonomy of at least $30 \mathrm{~min}$.

The Vibrotest software installed on the server is organized according to three data acquisition strategies, each storing files in pre-defined directories:

- “Threshold” acquisition strategy. DAQ n ${ }^{\circ} 1$, connected to the accelerometers, is programmed to continuously record when a seismic event occurs and exceeds a pre-defined threshold value, the latter being modifiable by the software; data from the LVDT transducers are also recorded with the same sampling frequency of accelerations. Besides the threshold value, that can be simultaneously settled for 3 different channels, it is possible to modify the acquisition frequency, the pre-trigger and post-trigger time values.

- “Periodical” acquisition strategy. DAQ n 2 is programmed to store every 6 hours the mean values, computed on a $60 \mathrm{sec}$ time interval, of the signals provided by the displacement transducers, the thermo-hygrometers and the barometer.

- "Continuous time" acquisition strategy. DAQ $\mathrm{n}^{\circ} 2$ is also programmed to record, over a 10 minutes period, the mean value and standard deviation of the signal produced by the tachy-gonio-anemometer, the minimum and maximum wind velocities and the percentages of time the wind blows from a direction falling within the 16 sectors of wind rose.

\subsection{Data Processing of the "Periodical" Acquisition Strategy}

This section shows the processing of data recorded by the "periodical" acquisition strategy during two long time intervals: February-March 2012 and October-March 2013. As specified in paragraph 3.2, the radial and tangential relative displacements in the seismic isolators (i.e., the relative displacements between the column top and the correspondent point at the intradox of the base ring) are measured by the columns (3), (9), (14) and (20) placed at the cardinal points. The transducers' range is $\pm 150 \mathrm{~mm}$ in tangential direction and $\pm 200 \mathrm{~mm}$ in radial direction, and the positive sign of the measurements is assumed so that: 
- an increment of radial displacement recorded by the sensor corresponds to an outward dome displacement with respect to the column (that is, an expansion of the dome);

- an increment of tangential displacement recorded by the transducer corresponds to a clockwise dome displacement in plan, with respect to the column.

As regard the thermo-hygrometers, 4 of them are installed close to the displacement transducers, while the fifth is mounted at the top of the structure. As easily expected, when the temperature increases, the dome and consequently the prestressed base ring expand, but, vice versa, they contract when the temperature decreases.

Figure 12(a) and Figure 12(b) have the date on the abscissa axis while the
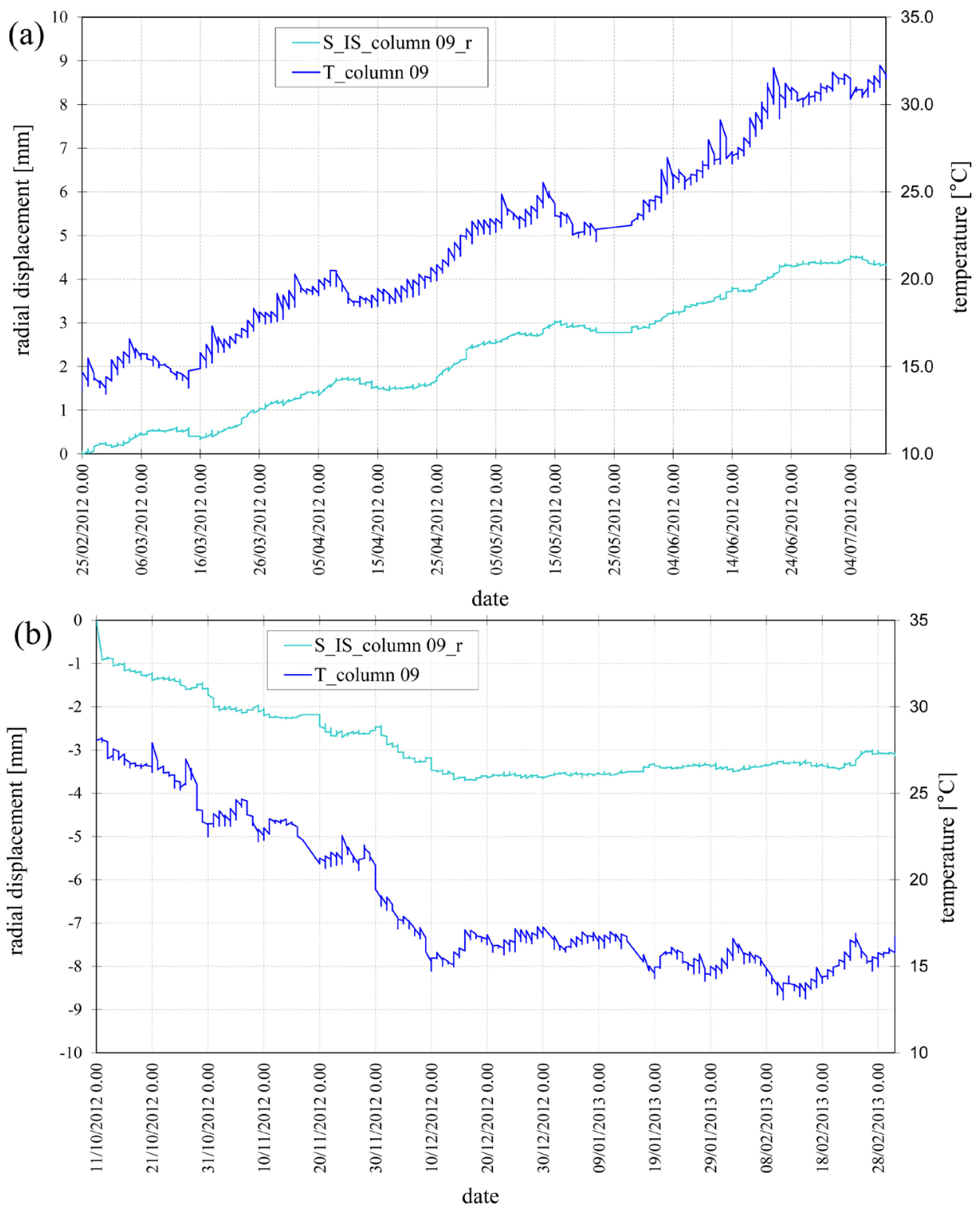

Figure 12. Radial displacements (S_IS) and temperature (T) on column 9 during the period (a) 25/02/2012-10/07/2012 and (b) 11/10/2012-03/03/2013. 
radial displacement and the temperature (measured at one of the four columns) are reported, respectively, on the left ordinate axis and on the right ordinate axis. The variation of temperature is discontinuous due to the daily thermal range: on each day, 4 surveys are made every 6 hours.

In the first analysed time interval (Figure 12(a)—from 25/02/2012 to 10/07/2012) the temperature increases: a positive radial displacement of nearly $4.5 \mathrm{~mm}$ corresponds to a positive $\Delta T$ of approximately $18^{\circ} \mathrm{C}$.

On the contrary, during the second observed time interval (Figure 12(b)-from $11 / 10 / 2012$ to $03 / 03 / 2013$ ), the temperature decreases: a dome contraction of about $3 \mathrm{~mm}$ corresponds to a temperature reduction of approximately $12^{\circ} \mathrm{C}$.

Compared to the restraint condition in radial direction, the Sanctuary's dome is free to move under thermal variations, less than the contrast action exercised by the friction force in the isolators. If the dome was free to move in space, the radial deformation $\varepsilon_{r}^{\Delta T}$ would be equal to:

$$
\varepsilon_{\Delta T}=\frac{\Delta R}{R}=\alpha \cdot \Delta T
$$

where

$R=34 \mathrm{~m}$ is the radius of the base ring,

$\Delta R$ is the radius' variation,

$\alpha=1 \times 10^{-5} \mathrm{C}^{-1}$ is the thermal expansion coefficient of concrete.

As this behaviour is prevented by the friction reaction of the isolators, the dome's base ring is subjected to a coaction state characterized by a compression axial force for positive thermal variations.

The maximum force $F_{a}$ developed by the isolators (static friction force) is estimated by considering a steel-teflon friction coefficient equal to $1 \%$ :

$$
F_{a}=\frac{W}{n} \cdot 1 \% \approx 100 \mathrm{kN}
$$

where:

$n=22$ is the number of bearings,

$W=220,000 \mathrm{kN}$ is the total weight assumed for the dome.

The maximum values assumed by the coaction $p$ and the deformation $\mathcal{E}_{e}$ correspond to the achievement of forces $F_{a}$ in the isolators:

$$
\begin{gathered}
p^{\max }=\frac{F_{a} \cdot n}{2 \pi R} \\
\varepsilon_{e}^{\max }=\frac{p^{\max } \cdot R}{E A}
\end{gathered}
$$

Accordingly, in the condition when the dome is constrained towards its sliding, the elastic deformation is equal and opposite to the thermal one; the thermal variation $\Delta T^{s}$ responsible of the dome's sliding can be deduced by equating the above deformations (elastic and thermal):

$$
\varepsilon_{e}^{\max }=\varepsilon_{\Delta T}^{\max } \Rightarrow \frac{p^{\max } \cdot R}{E A}=\alpha \cdot \Delta T^{\text {scorr }}
$$


Therefore, the force $F_{a}$ is achieved at a thermal variation of about $0.22^{\circ} \mathrm{C}$ in the base ring:

$$
\Delta T^{s c o r r}=\frac{p^{\max } \cdot R}{E A \cdot \alpha}=0.22^{\circ} \mathrm{C}
$$

The value $p^{\max }$ is equal to $\pm 10 \mathrm{~N} / \mathrm{mm}$ and determines the maximum stress of $\pm 350 \mathrm{kN}$.

Figure 13 shows that the dome's behaviour under the effect of temperature is not perfectly symmetric: although radial deformations at the monitored columns have the same trend during the time interval, for some columns the above deformation is higher (Figure 13(a)), and small tangential displacements are also recorded (Figure 13(b)). This can be due to lightly non-uniform distribution of temperature (Figure 13(c)) between measurement points and to the structural asymmetry both in terms of isolator's reaction and friction coefficient.

The following theoretical expression, which links the radial displacement to the temperature gradient, is obtained by Equation (7):

$$
\varepsilon_{\Delta T}^{\text {theor }}=\frac{\Delta R}{R}=\alpha \Delta T \Rightarrow \frac{\Delta R}{\Delta T}=\alpha R=34 \times 10^{-2}=0.34 \mathrm{~mm} /{ }^{\circ} \mathrm{C}
$$

This relationship can be compared to experimental outcomes, obtained by plotting the variation of radius $\Delta R$ as function of $\Delta T$ (Figure 14(a)), for each column. The values $\varepsilon_{\Delta T}^{\text {exp }}$ deduced through linear regression curves for all columns are always lower than the theoretical value (Figure 14(b)). Such deviation is caused by the stiffening contribution of the upper dome toward the base ring that is not free to move.

\subsection{Data Processing of the "Continuous Time" Acquisition Strategy}

The "continuous time" acquisition strategy is devoted to survey the physical quantities relative to the wind blowing outside the dome: it is possible to know not only the intensity wind parameters (minimum and maximum values, mean value and standard deviation of wind velocity), but also its direction within the wind rose.

Figure 15 represents the variation of wind velocity during the period from $06 / 03 / 2012$ to $18 / 03 / 2012$ : the maximum velocity achieves the value $30 \mathrm{~m} / \mathrm{s}$ while the minimum value on the acquired interval (i.e., $10 \mathrm{~min}$ ) is always equal to zero. Besides, the more windy time interval corresponds to two days of March $\left(9^{\text {th }}\right.$ and $\left.10^{\text {th }}\right)$.

In Figure 16, a restricted time window, corresponding to day 06/03/2012, is selected to analyze the distribution of wind direction. Figure 16(a) shows the percentages of time (computed every $10 \mathrm{~min}$ ) the wind blows from a direction falling within the 16 sectors of wind rose. On the other hand, Figure 16(b) represents the same percentages for each rose's sector with time. Obviously, the sum of percentage values in every time instant is equal to 1 . In the sample day, wind involved only the $\mathrm{N}$ and NNE directions. 

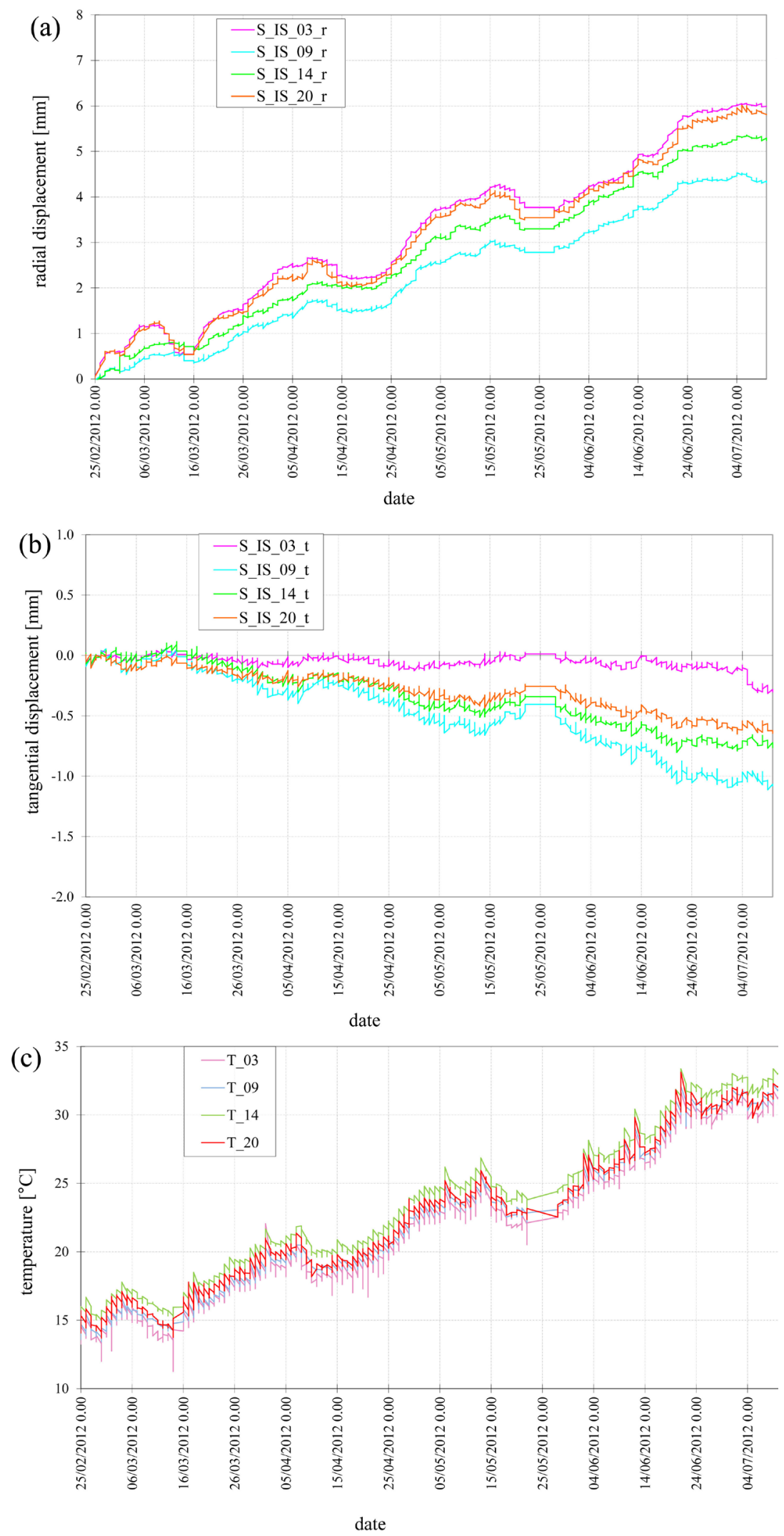

Figure 13. Radial displacements (a), tangential displacements (b), temperature (c) on columns 3, 9, 14, 20 during the period 25/02/2012-10/07/2012. 
(a)

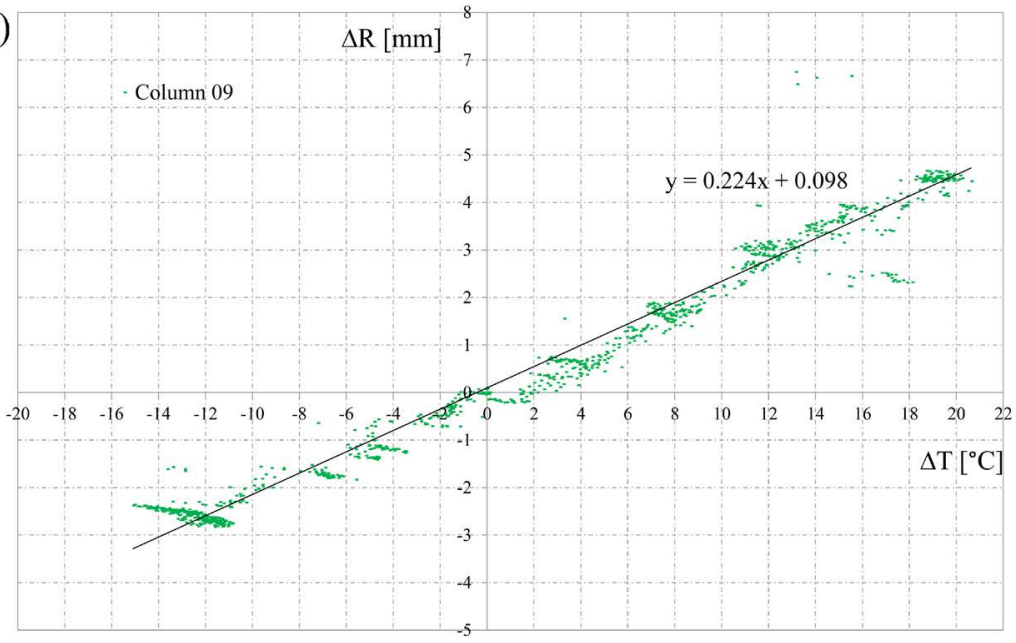

(b)

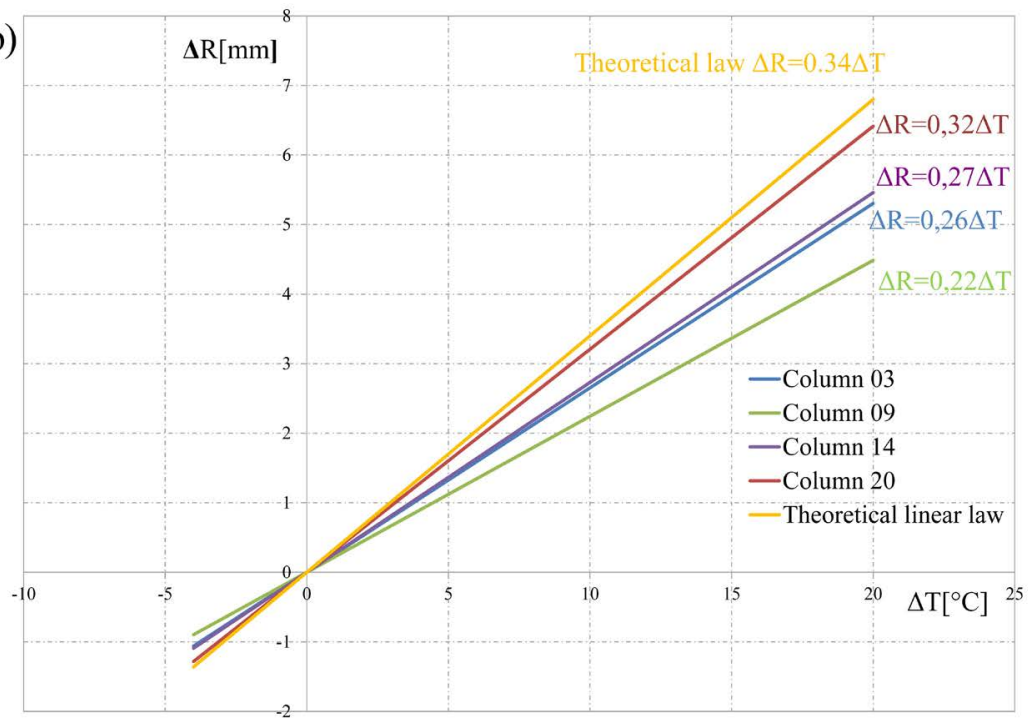

Figure 14. $\Delta R$ vs. $\Delta T$ for the column 9 (a) and comparison of experimental relations $\Delta R$ vs. $\Delta T$ with theoretical ones $\Delta R$ vs. $\Delta T(\mathrm{~b})$.

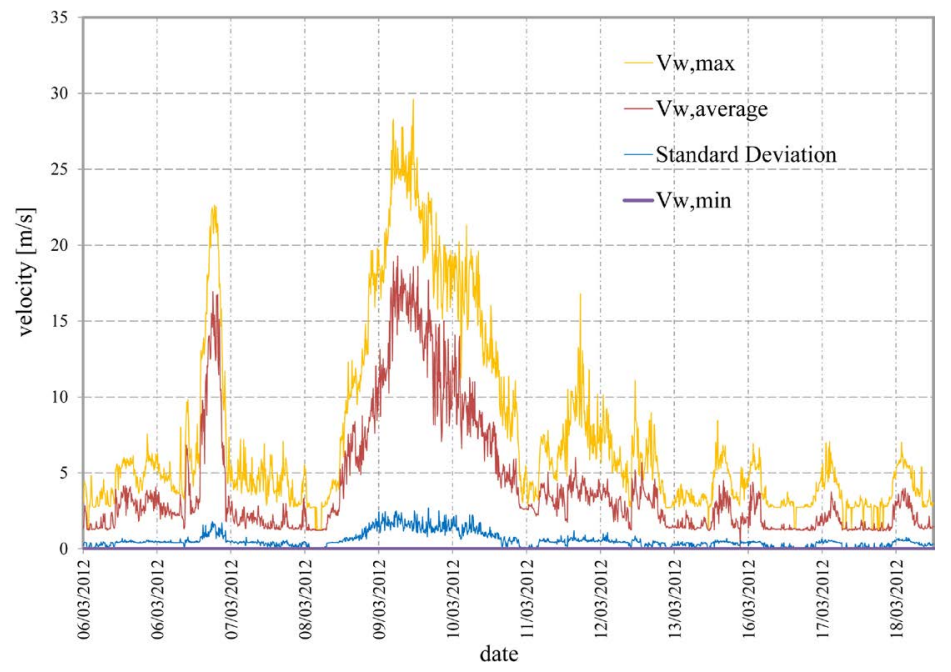

Figure 15. Characteristics of wind velocity during the period 06/03/2012-18/03/2012. 
Figure 17 displays the same processed data for day 12/03/2012: the above diagrams and the examination of the other wind data demonstrate that the selected site is characterized by wind mainly blowing along $\mathrm{N}$ and NNE directions.

The availability of wind data could be very useful in the perspective of applying operational dynamic identification techniques with environmental input.

\subsection{Data Processing of the "Threshold" Acquisition Strategy}

Two low magnitude seismic events recently occurred more than $100 \mathrm{~km}$ away from Syracuse and triggered the Sanctuary's monitoring system. The first one, of
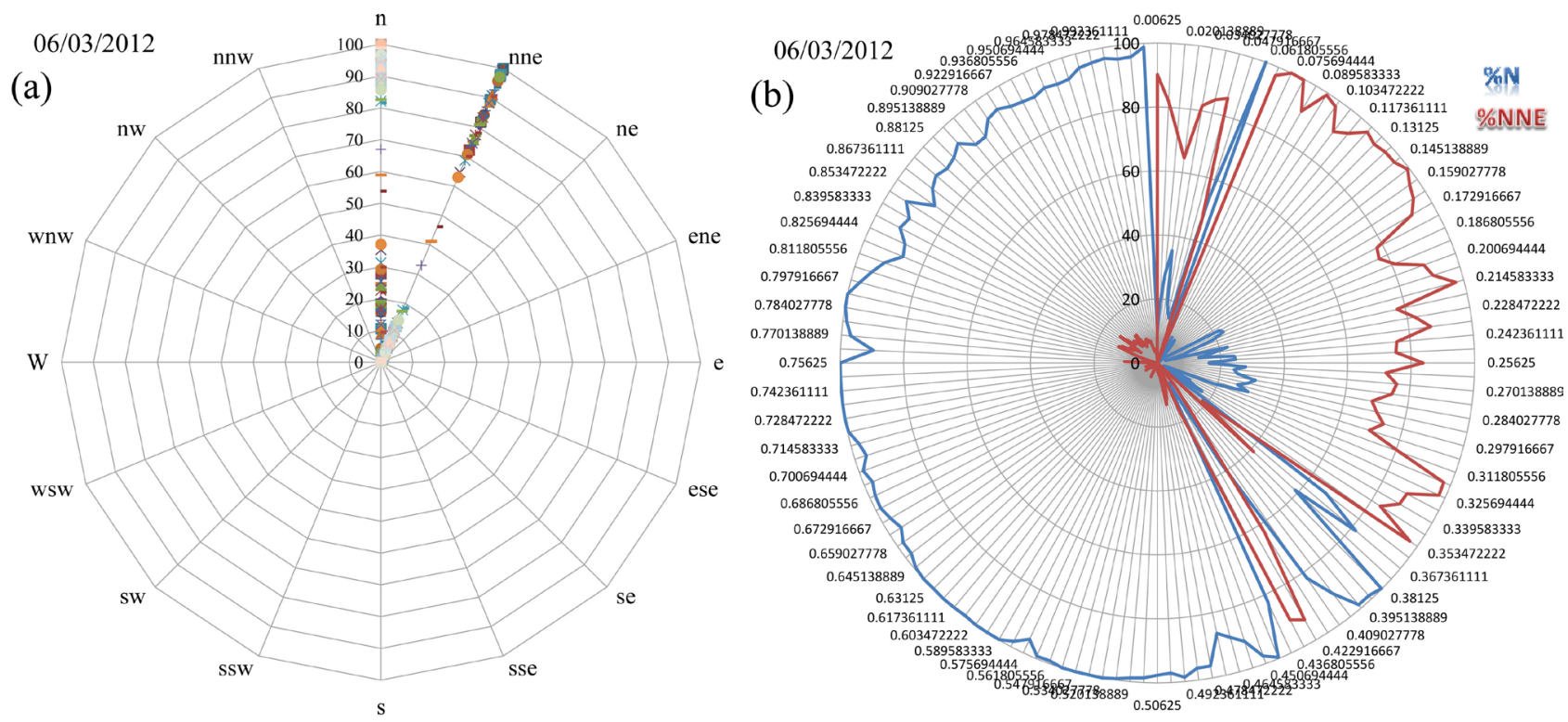

Figure 16. Time percentage of each wind direction at any detection (a) and variation, for each activated direction, of the percentage in 24 hours on 06/03/2012 (b).

(a)

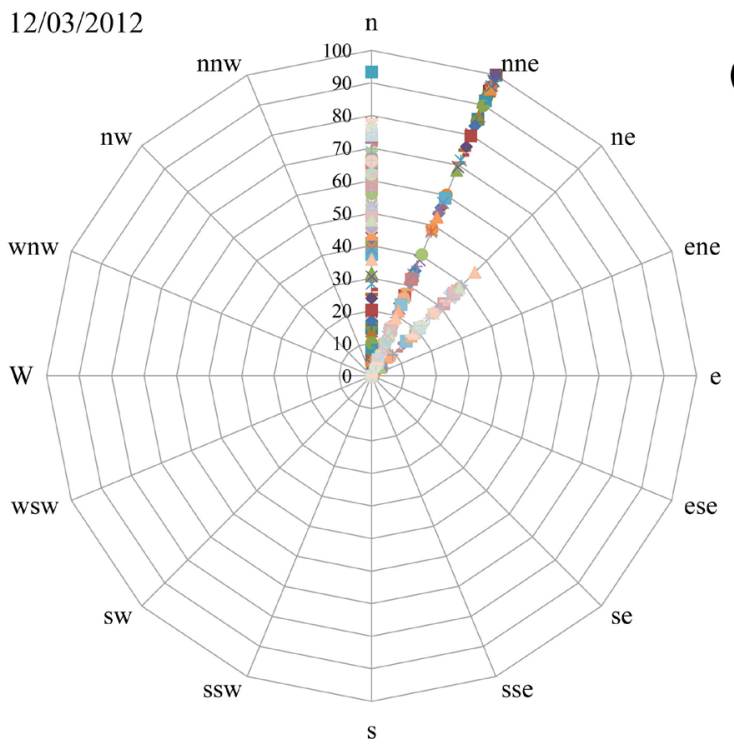

(b)

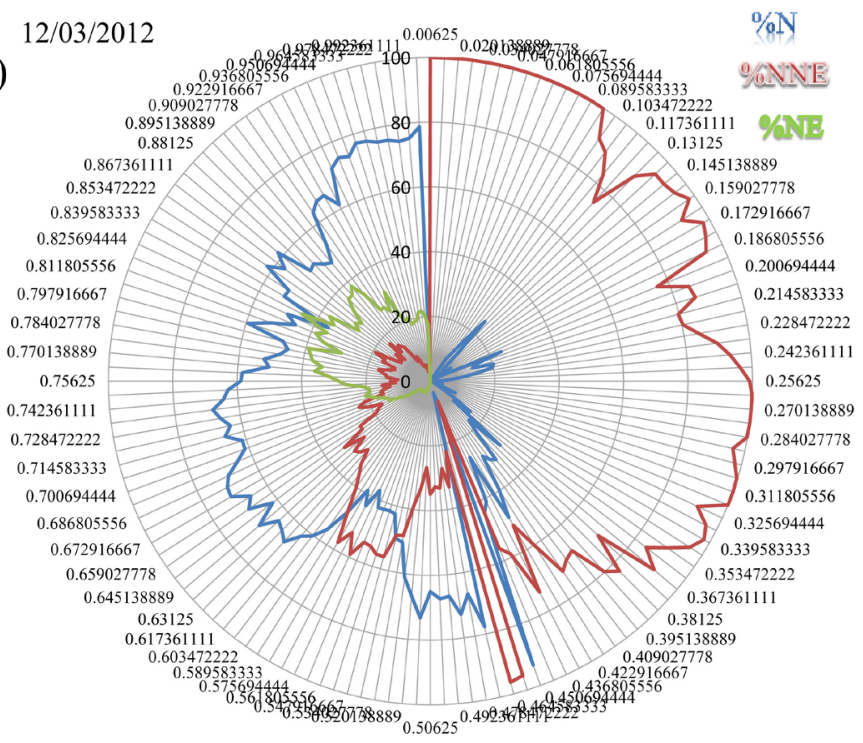

Figure 17. Time percentage of each wind direction at any detection (a) and variation, for each activated direction, of the percentage in 24 hours on 12/03/2012 (b). 
magnitude $M_{L} 3.9$, was recorded on November $22^{\text {th }} 2012$ in the seismic area of volcano Etna; the second one of $M_{L} 4.3$ was recorded on January $4^{\text {th }} 2012$ in the seismic region of Nebrodi Mounts. They activated the "threshold" acquisition strategy, due to the overcoming of the threshold value $(0.004 \mathrm{~g})$ settled for the horizontal accelerations at the dome's top, even if no relative displacement was measured at the isolators' level.

The significant distance from the above epicentres produced very low accelerations at the site: the maximum acceleration at Crypt level (elevation $-10.40 \mathrm{~m}$ ) is approximately $0.002 \mathrm{~g}$ during the first earthquake (Figure 18(a)) and $0.001 \mathrm{~g}$ during the second one (Figure 18(b)), with a very low signal to noise ratio (SNR).

The accelerations corresponding to column 12 at elevations $3.76 \mathrm{~m}$ (top of the column: $L O W$ ), $4.00 \mathrm{~m}$ (top of the isolator: $U P$ ), $16.40 \mathrm{~m}$ (intermediate ring: $I R$ ) and at structure's top (TOP) are only shown in the following for the most interesting seismic input, i.e. the one occurred in November 2012 (Figure 19).
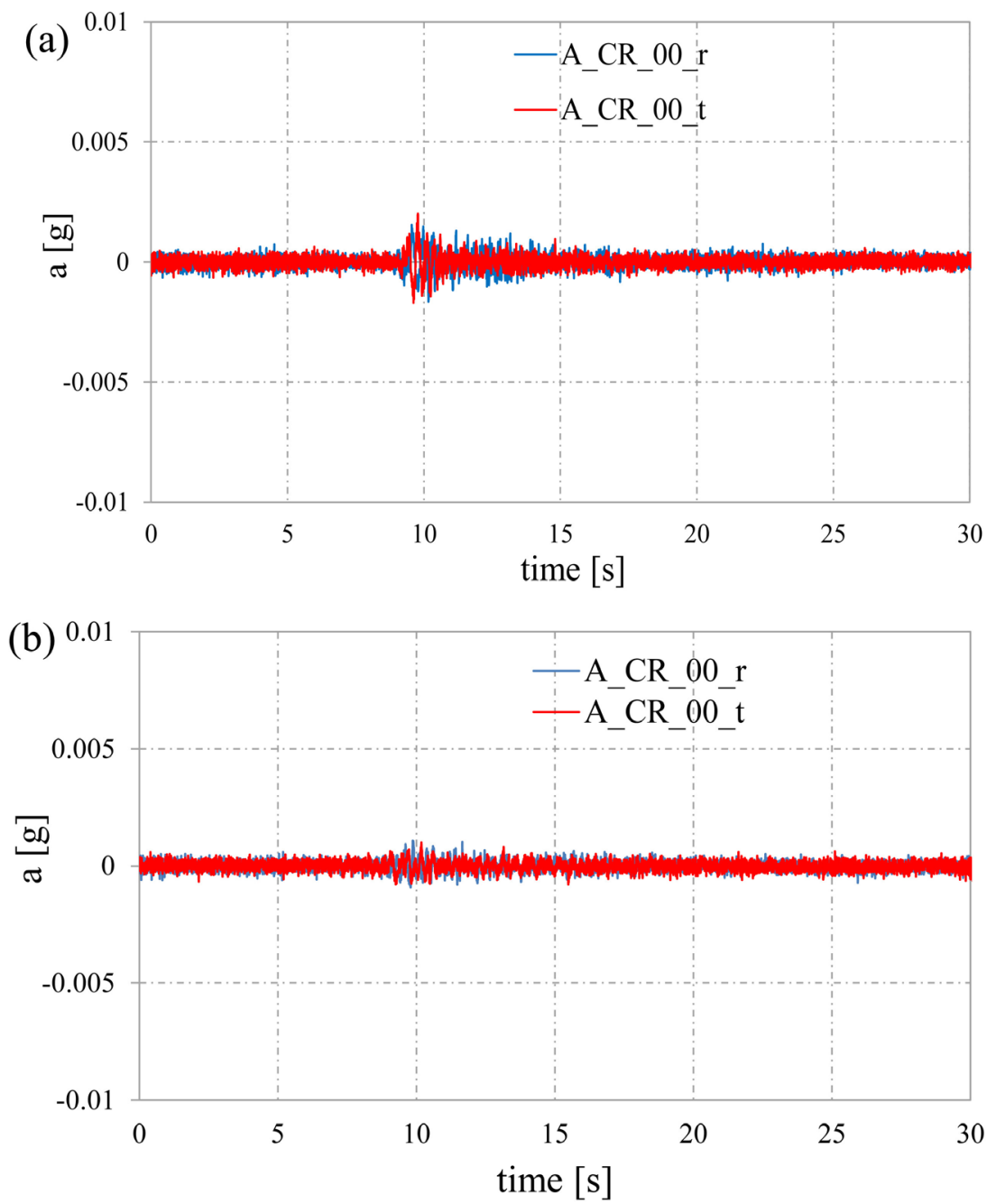

Figure 18. Radial and tangential accelerations in Crypt for the earthquake of 22/11/2012 (a) and that one of $04 / 01 / 2013$ (b). 

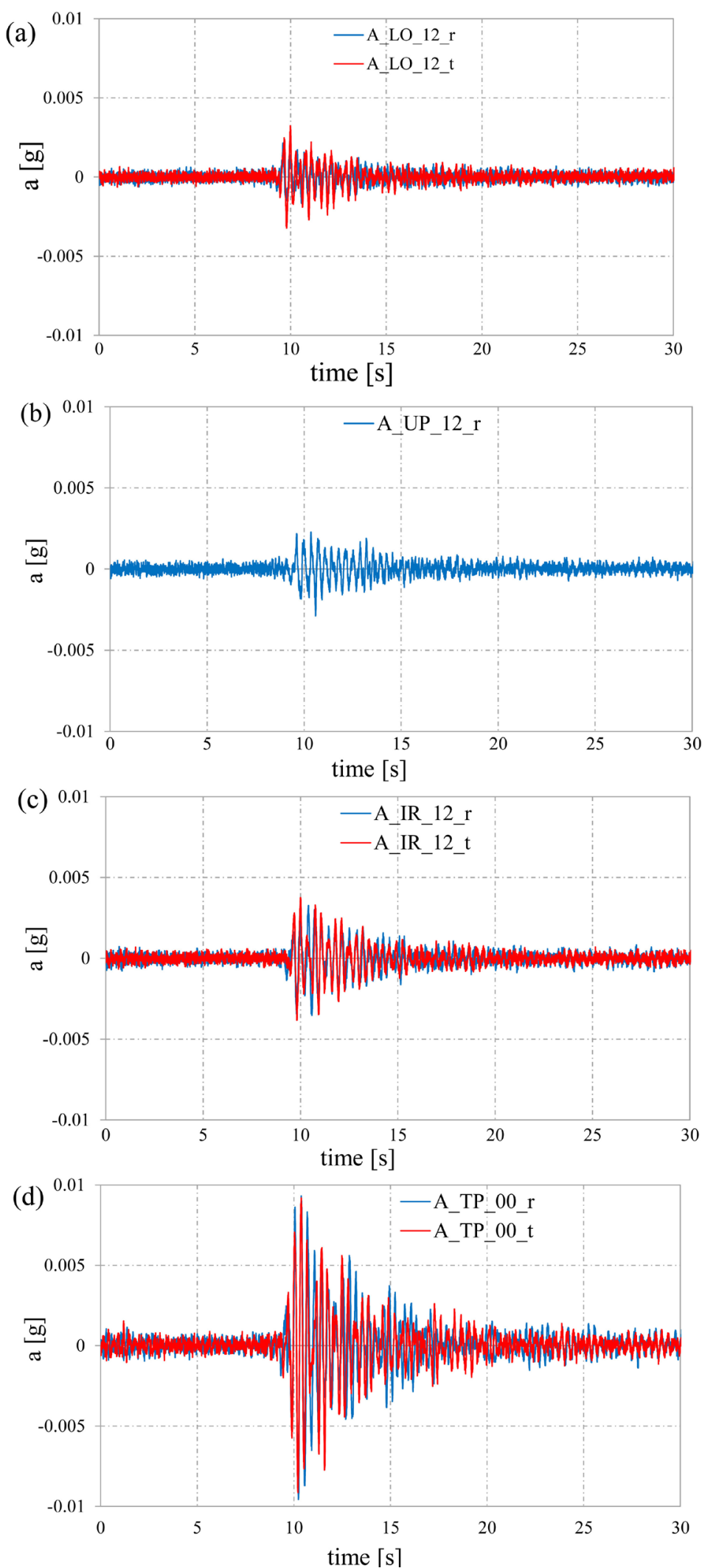

Figure 19. Earthquake of 22/11/2012-Radial and tangential accelerations along the height at different elevations: $3.76 \mathrm{~m} \mathrm{(a),} 4.00 \mathrm{~m} \mathrm{(b),} 16.40 \mathrm{~m}$ (c), top (d). 
The tangential component at elevation $4.00 \mathrm{~m}$ is not shown since the signal was corrupted. The maximum accelerations range from approximately $\pm 0.002 \mathrm{~g}$ at Crypt level to $\pm 0.01 \mathrm{~g}$ at the top. The coincidence of the two acceleration time-hystories recorded at top and bottom of the isolation system, confirms that the dome is fixed, as demonstrated by no relative displacement in the isolators.

On the other hand, a certain amplification of vertical accelerations is shown along the height due to inner flexibility of the isolation system: the maximum value at the intermediate ring and at the top of the structure are comparable, i.e. in the order of $\pm 0.003 \mathrm{~g}$.

\section{Dynamic Identification and Analysis of the Isolated Structure}

\subsection{Description of the FE Model of the Sanctuary}

The Upper Temple of the Sanctuary has been modelled through the Finite Element Structural Analysis Program SAP2000 [18]: this model considers the truncated-conical dome with its geometrical and structural complexity, the isolation system and the columns below (Figure 20).

The reinforced concrete columns are modelled by 22 "beam" elements having variable cross-section and uniformly distributed along the perimeter of the Upper Temple. The 22 antiseismic bearings installed on the columns are modelled by non-linear "nllink" elements, each of them connecting a point at top of the column that corresponds to the isolator's center (i.e., bonded to the isolator's barycentre by a "body" constraint), to the relative point at the base of the dome. The "nllink" elements have the following properties:

- in vertical direction, an elastic stiffness is considered which represents the experimentally measured bearings' vertical stiffness $k_{\mathrm{v}, \mathrm{n}}=9000 \mathrm{kN} / \mathrm{mm}$ [15];

- in radial direction, a friction link defined through a friction coefficient of $1 \%$, equal to the experimental value determined for the sliding of a steel surface

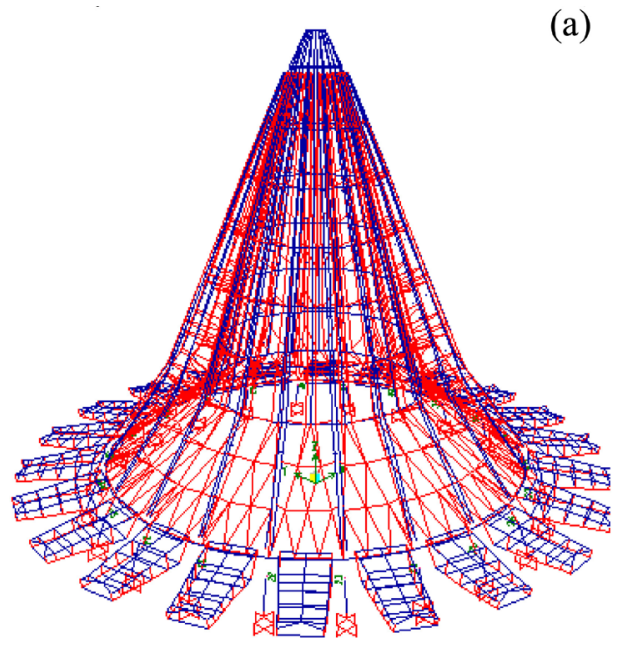

(a)

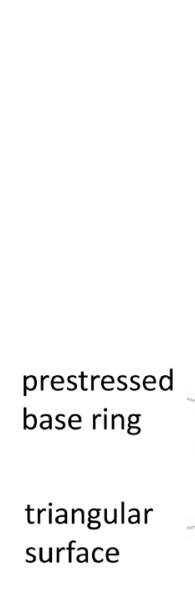

(b)

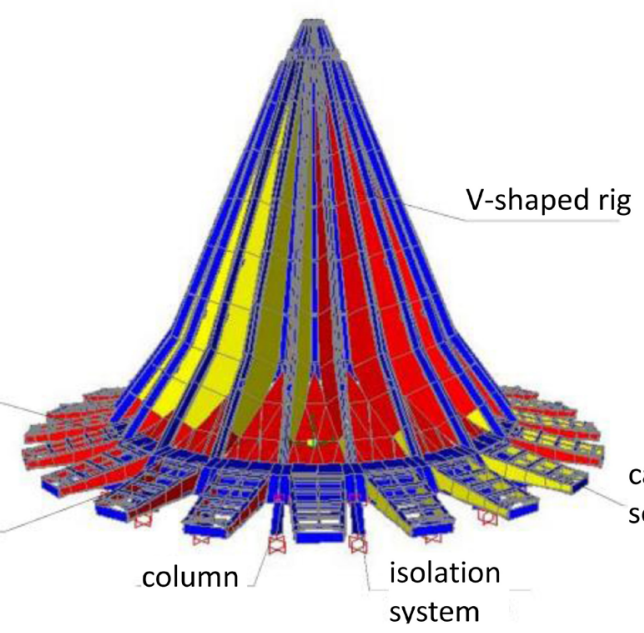

cantilevered boxsection member

Figure 20. Complete model of the Sanctuary (a) and extruded view (b). 
on a lubricated teflon surface [19]);

- in tangential direction, an elasto-plastic Wen-type law (Figure 21) with parameters obtained by experimental tests, taking into account that each antiseismic device includes 16 "moon's sickle" steel elements working in parallel [20]). The first yielding force yield has been computed multiplying by 16 the experimental value $\left(F_{\mathrm{p}}=40 \mathrm{kN} \times 16=640 \mathrm{kN}\right)$ obtained by a test performed on a "moon's sickle" element (Figure 22); the initial elastic stiffness $k$ is equal to 16 times the corresponding experimental stiffness $\left(k_{\mathrm{e}}=4350\right.$ $\mathrm{kN} / \mathrm{m} \times 16=69,600 \mathrm{kN} / \mathrm{m}$ ); the post-yielding stiffness ratio $\times k$ has been calculated multiplying by 16 the relative experimental average value derived by the approaching and leaving/deviation phases between the 2 "moon's

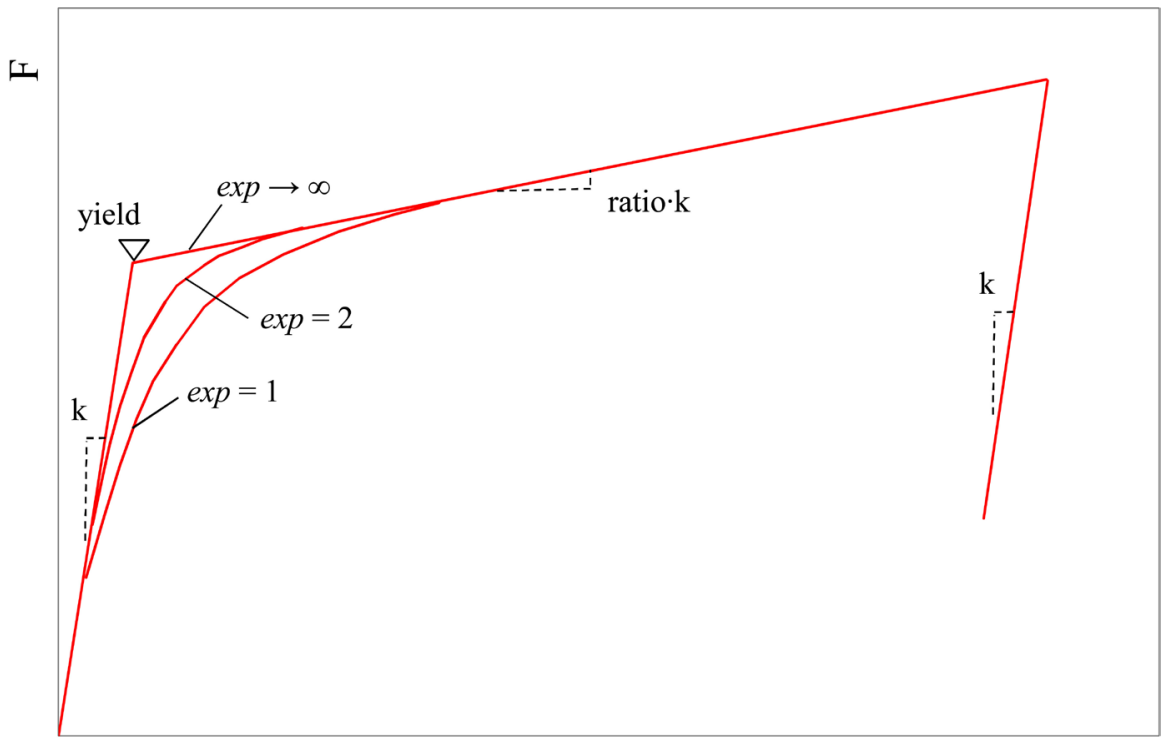

Figure 21. Characteristic parameters of the elasto-plastic relationship of Wen type.
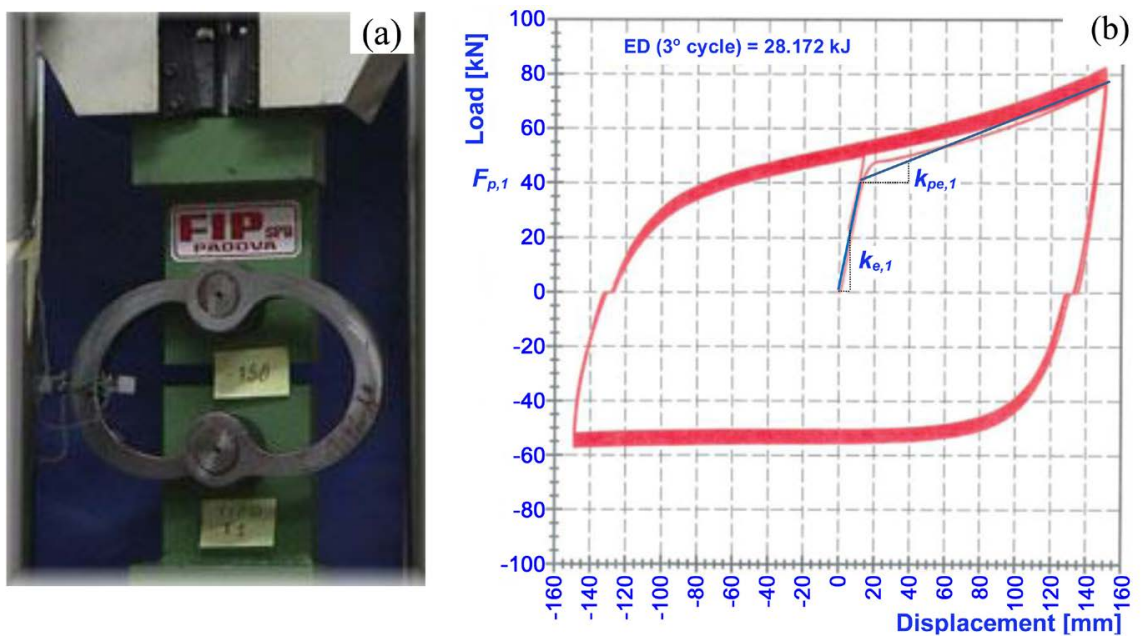

Figure 22. Experimental test on a couple of elasto-plastic dissipators (a) and hysteretic cycle relative to a single elasto-plastic dissipator (b). 
sickle" ends $\left(k_{\mathrm{pe}}=110 \mathrm{kN} / \mathrm{m} \times 16=1778 \mathrm{kN} / \mathrm{m}\right)$ while the parameter exp for the transition to the non-linear phase is settled equal to 2; the first yielding displacement has been found equal to $1.5 \mathrm{~cm}$ from the experimental cycle.

It is worth to point out that, for low intensity earthquakes, unless the inertia force developed in the superstructure reaches the friction static resisting force at the isolation level, the isolation system represents a fixed restraint for the dome with respect to the columns. Therefore, the isolation system is activated only when the seismic intensity determines the sliding of the dome on the teflon surfaces.

The two straight parts of the 22 externally cantilevered ribs, having $\mathrm{V}$ cross-section and developing from the prestressed base ring to the second-last ring at the top, are simulated by "shell" elements of thickness $20 \mathrm{~cm}$.

The 8 annular rings, seven of them connecting the ribs, are modelled through "beam" elements: the prestressed concrete base ring and the last two rings towards the top are characterized by alternating solid section and hollow section parts along the circumference, while the other 6 rings have full section.

The generic sub-horizontal external cantilever, placed between two adjacent columns, is modelled by using "beam" elements for the longitudinal and transversal beam elements of the upper and lower floors and "shelp" elements for the perimetral closing concrete walls.

The plane zones bounded by the ribs are simulated by sub-horizontal r.c. slabs having variable thickness. The parts of dome surface (triangular in plan), delimited by two adjacent flaps between the base ring and the intermediate ring, are modelled by 9 triangular "shelp' elements having an equivalent thickness of 35 $\mathrm{cm}$, with respect to the area of the section that is actually boxed and ribbed. The artistic steel structure at the top and the other glass windows placed between the flaps, are simulated by concentrated masses acting on nodes.

The FEM complete model of the Upper Temple overall is characterized by 6059 nodes, 2592 frame elements, 854 shell elements, 478 body constraints, 22 diaphragm constraints (representative of the diaphragm behaviour of the boxed cantilevered elements' floors) and 22 nllink elements. The definition of the complex geometry has required the introduction of 64 coordinate systems.

\subsection{Application of Simple Dynamic Identification Techniques}

The analysis of the signals recorded during the recent seismic inputs (see $\$ 53.6$ ) allowed to apply some dynamic identification techniques [21] of the examined worship structure under environmental excitations (Operational Modal Analysis-OMA).

Figure 18 highlights the low value of signal/noise ratio (SNR) that has to be carefully taken into account during analysis and processing of signals. The results shown in the following refer to signals acquired during the seismic event occurring on November $22^{\text {th }} 2012$. Response to earthquake of January $4^{\text {th }} 2013$ mainly confirmed the same results. The structural response has been examined 
in terms of accelerations, either in time or in frequency domain.

Accelerations are examined at points placed along column 12 at different elevation, both in vertical and radial/tangential directions (Figure 23). The radial and tangential accelerations (channel up_12_t isn't shown due to significant noise) increase along height up to maximum values of approximately $0.01 \mathrm{~g}$ at top.
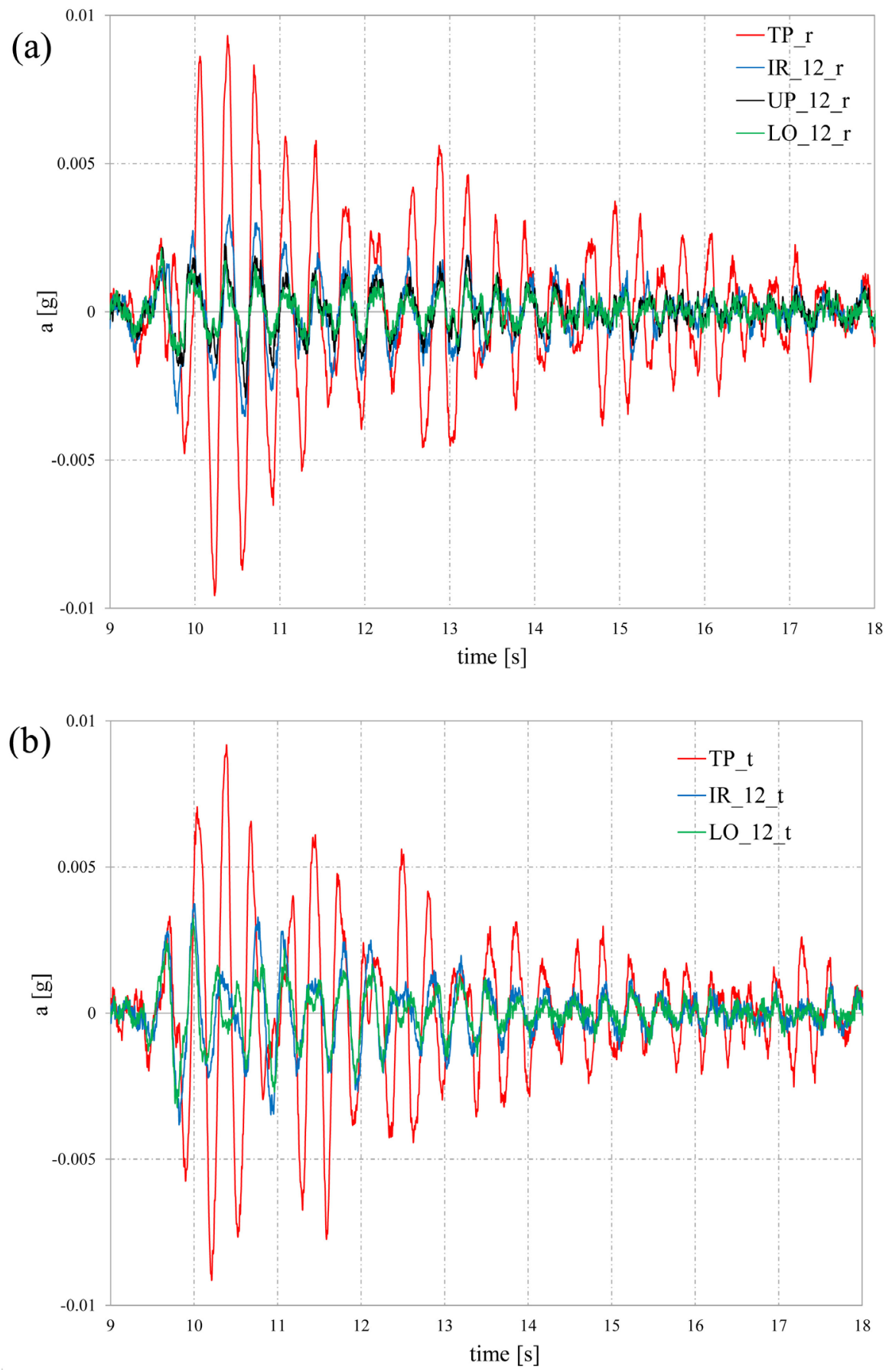

Figure 23. Accelerations at different elevations along the vertical direction at column 12 in radial (a) and tangential (b) direction. 
A first evaluation of the structural vibration period has been obtained by dividing the time window characterized by a significant vibration of the structure by the corresponding number of cycles: a period $T \cong 0.35 \mathrm{sec}$ resulted, i.e. a frequency $f \cong 2.9 \mathrm{~Hz}$.

A careful examination of the radial and tangential acceleration components at the same elevation but projected along a common direction, shows that both signals are in phase and characterized by the same vibration frequency. Figure 24 shows the components of the radial and tangential accelerations measured at
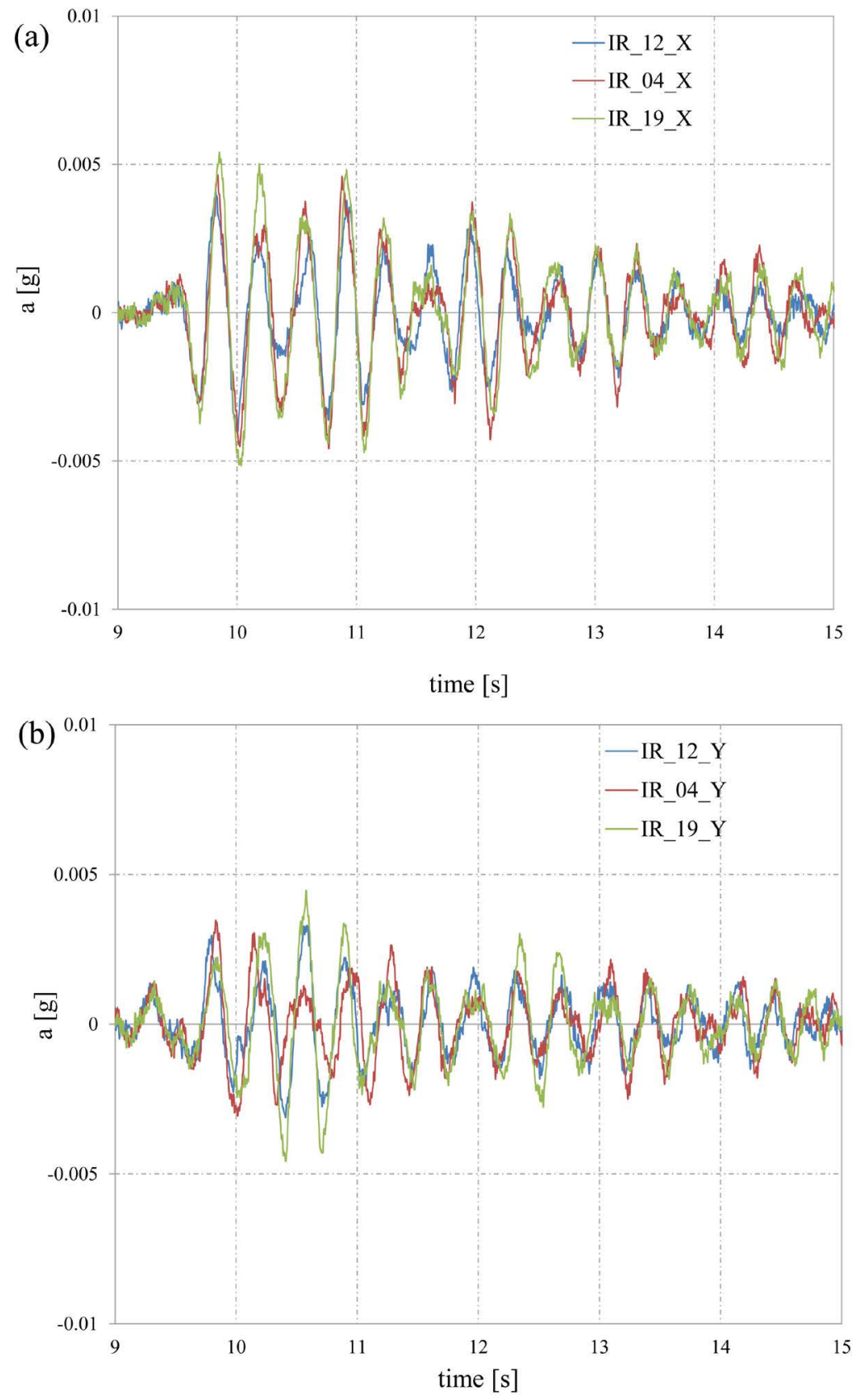

Figure 24. Accelerations along $X(\mathrm{a})$ and $Y(\mathrm{~b})$ of 3 measurement points at elevation $16.40 \mathrm{~m}$. 
intermediate ring's level by the considered 3 columns along the reference axes of the FEM model main coordinate system $(X, Y)$. It can be deduced that these points move as a rigid body with a minor rotational component.

Each signal has been processed in the frequency domain, as follows:

- a low-pass filter has been applied with a cutoff frequency of $20 \mathrm{~Hz}$;

- only the part of signal containing the effect of excitation has been analyzed (i.e., pre-trigger and post-trigger time intervals, defined within the acquisition strategy, have been deleted), to the aim of reducing the influence of noise on the successive analysis of frequency content;

- the "windowing" technique (having Hanning type operation) has been applied to the acceleration signals along the time interval $6-20 \mathrm{~s}$, in order to remove "leakage" problems.

The FFT function (Fast Fourier Transform) has been determined for all handled acceleration signals, on a properly computed number of points for the considered time window (Figure 25).

The FFT functions have been analysed in terms of amplitude and phase with the aim of detecting information to define the mode shapes of the structure.

FFTs of both radial (Figure 26) and tangential (Figure 27) components of all signals (Figure 24) highlight two main resonances. Due to axial symmetry of the structure, two vibration modes in two almost orthogonal directions correspond to each of those frequencies.

A Single Degree of Freedom analysis, based on the investigation of the FFT functions one by one, allowed to associate one mode shape to each resonance: the absolute value of displacement has been deduced from FFT amplitude, while its sign has been obtained from real and imaginary part components, at different elevations.

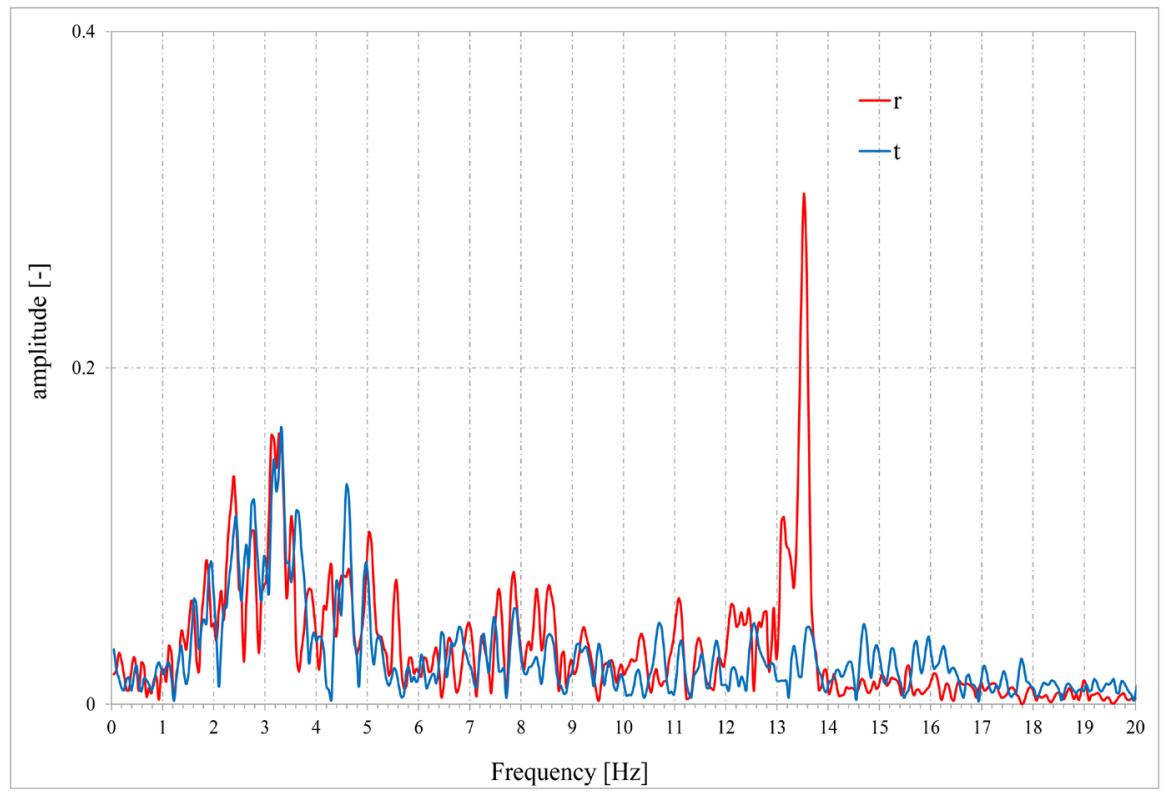

Figure 25. FFT of the base acceleration along directions $\mathrm{r}$ and $\mathrm{t}$. 

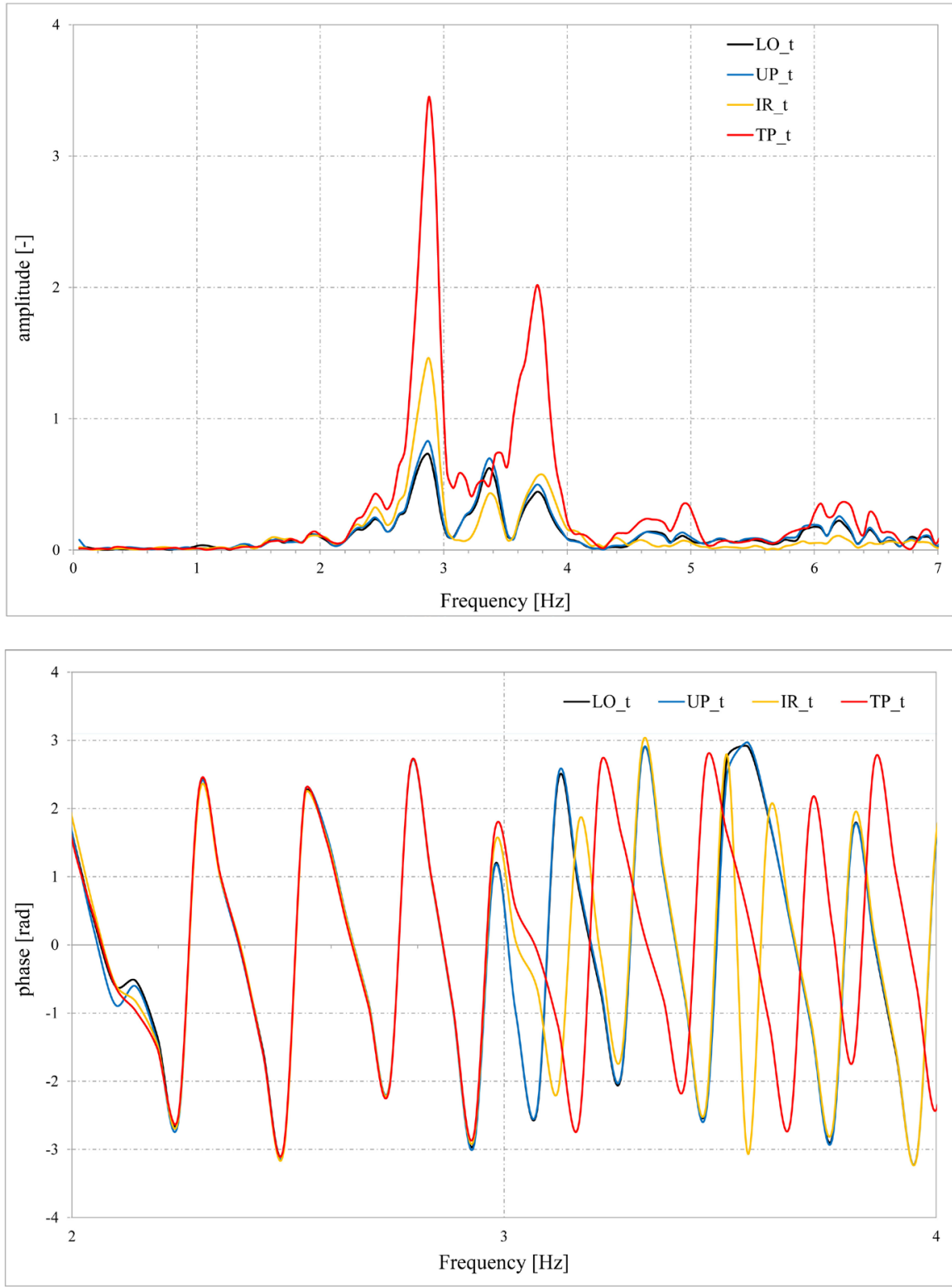

Figure 26. FFT of accelerations along the vertical direction at column 12 in direction t.

The first resonance at approximately $2.9 \mathrm{~Hz}$ corresponds to a first vibration mode, increasing amplitude and in phase displacements along the height in both directions. The mode shape is mainly of flexural type and has been detected drawing the in plane deformed shape (Figure 28) in such a way to comply with the conservation principle of the shape of each circular ring.

The second resonance at approximately $3.8 \mathrm{~Hz}$ is characterized by larger deformations between the intermediate ring level $(I R)$ and the top of the structure: since a phase change is observed at the top of the dome with respect to lower levels (sign variation of the real to imaginary parts in Figure 26 and Figure 27) the resulting mode shape corresponds to a second flexural mode, as shown in Figure 29. 

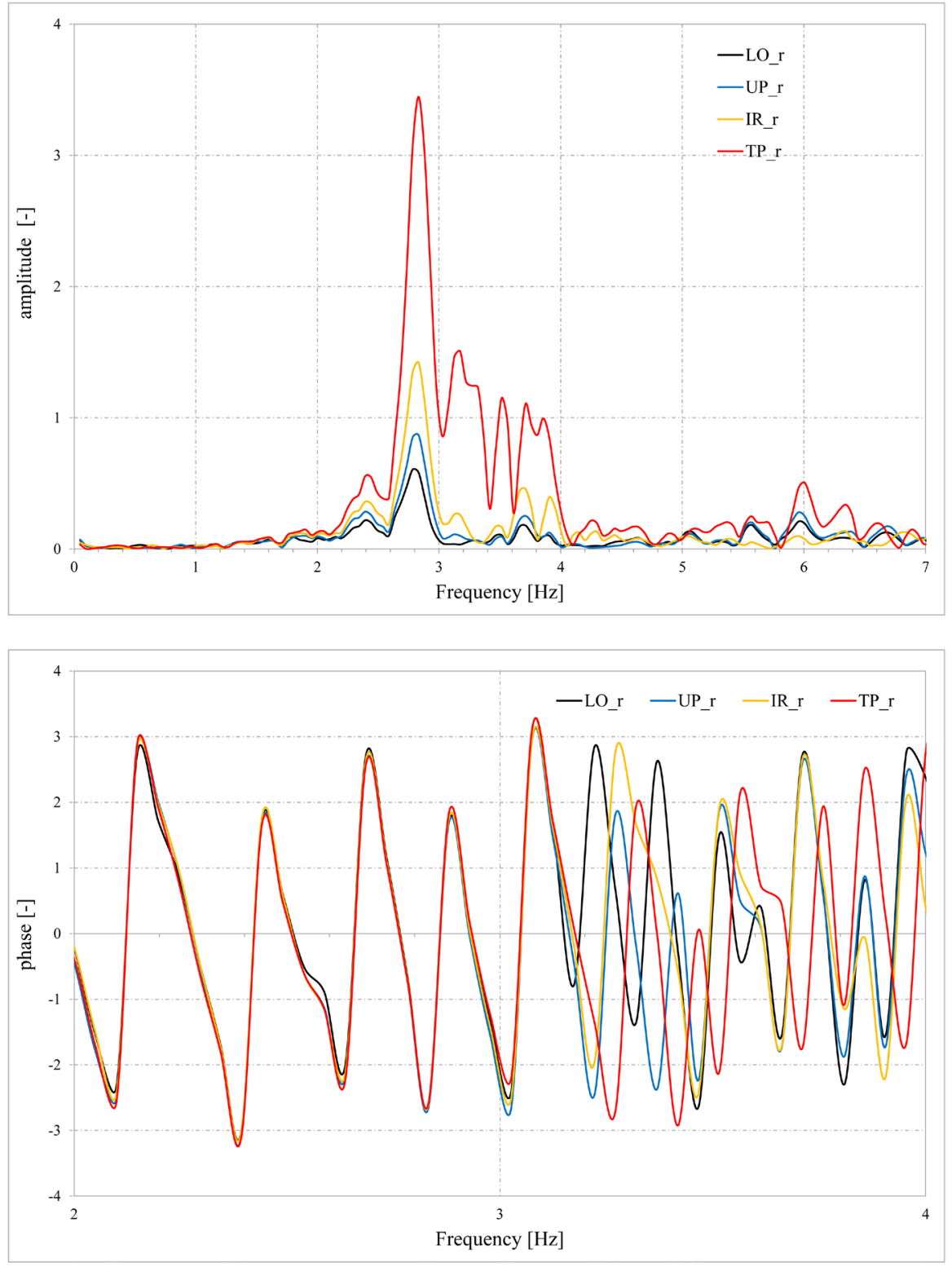

Figure 27. FFT of accelerations along the vertical direction at column 12 in direction $\mathrm{r}$.

\section{PLAN VIEW}

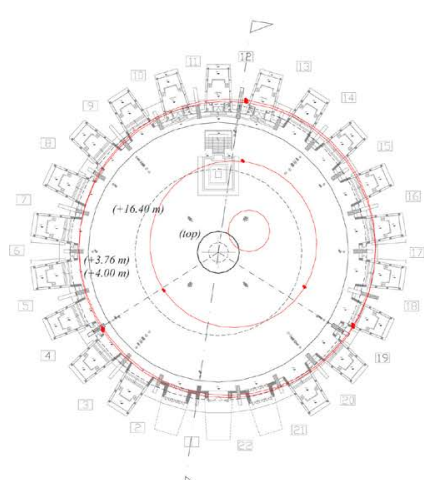

RADIAL DISPLACEMENTS

Column 12

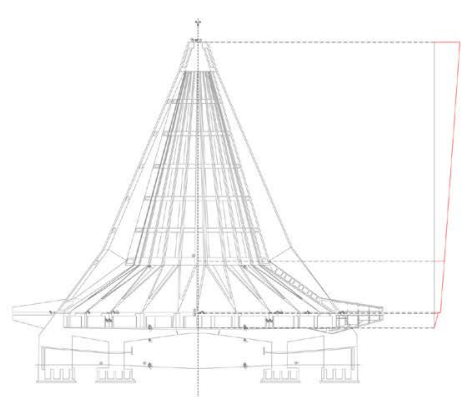

TANGENTIAL DISPLACEMENTS

Column 12

Figure 28. Modal deformation (in red) at $2.9 \mathrm{~Hz}$ in plan and cross-section at column 12. 


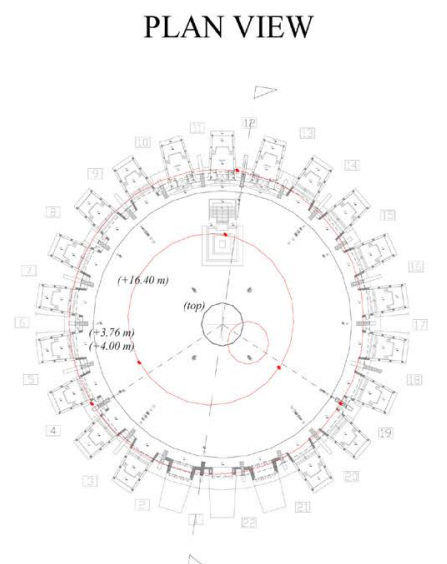

RADIAL DISPLACEMENTS Column 12

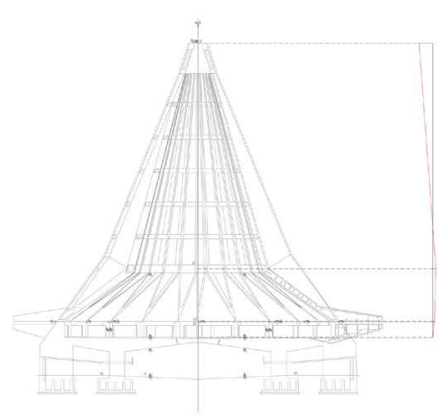

TANGENTIAL DISPLACEMENTS

Column 12

Figure 29. Modal deformation (in red) at $3.8 \mathrm{~Hz}$ in plan and cross-section at column 12.

Considering that, except for a small mass eccentricity in one direction, the structure is polar-symmetric and the experimental results show a resonance at $2.9 \mathrm{~Hz}$ in both the radial and tangential directions on all measurement points, it is possible to deduce that this frequency corresponds to the first flexural mode in the two main orthogonal directions with the presence of a small torsional component in one of these. For the same reason, it can be deduced that the frequency $3.8 \mathrm{~Hz}$ corresponds to a second mode where the torsional component can be roughly estimated due to only one measurement point at the top of the dome.

\subsection{Calibration and Validation of the FEM Model}

The experimentally deduced dynamic properties have been used to calibrate the numerical model of the Sanctuary and to validate it afterwards. Even if the FEM model accurately reproduces the complex geometry of the structure as described in Paragraph 4.1, there are two main parameters affected by some degree of uncertainties in the calibration job, besides an unavoidable uncertainty on the real constraint conditions among several structural elements. The first parameter is the unknown young modulus of concrete $E_{\mathcal{c}}$ which influences the overall stiffness: compared to the design value of the compressive strength $R_{c k}=35 \mathrm{MPa}$, the crush tests performed during the construction of the structure provided quite higher mean and maximum strength values $\left(R_{c m}=60 \mathrm{MPa}\right.$ and $R_{c, \max }=90 \mathrm{MPa}$, respectively). As reported in [22], $E_{c}$ can be estimated in the range between 35.000 and 45.000 MPa corresponding to compressive strengths of 35 and $90 \mathrm{MPa}$, respectively. The maximum value, i.e. 45,000 $\mathrm{MPa}$, has been assumed in the numerical model. The second parameter is represented by the total mass of the dome due to the contribution of the 19 chapels suspended to the cantilevered box-section members, assuming all remaining structural elements been accurately modelled in terms of geometry and weight. A total mass of $21.890 \mathrm{t}$ has been considered, i.e., lower than the value $22.780 \mathrm{t}$ returned by the hydraulic jacks system during the rising of the dome [15]. The gap between these two values is due to the in- 
teraction of the chapels' floors and the connection joints with the basic stall of the Upper Temple during the rising operation.

After the calibration process, the modal analysis of the numerical model (restrained displacements of isolators) has led to the following results: the first flexural modes have the same vibration frequency of $2.8 \mathrm{~Hz}$ in both $X$ and $Y$ directions, with a minor torsional component along one of these. The torsional components along the flexural mode are due to about $0.8 \mathrm{~m}$ eccentricity of the center of mass in one direction. On the other hand, the first dominant torsional modes have been computed at at 3.0 and $3.8 \mathrm{~Hz}$, respectively. The second mainly flexural mode in one direction is at $4.1 \mathrm{~Hz}$. Table 1 collects main results from modal analysis:

The numerical vs. experimental model comparison is satisfactory for the first flexural mode in the two directions: numerical value $2.8 \mathrm{~Hz} v s$. experimental frequency $2.9 \mathrm{~Hz}$ (difference of 3\%) with a torsional component in one direction and a participating mass between 30 and $40 \%$. The second numerical flexural mode in one direction is at $4.1 \mathrm{~Hz}$, that is a frequency lightly higher than the experimental value $3.8 \mathrm{~Hz}$ of approximately $8 \%$, even if the participating mass is only $5 \%$. From the experimental analysis, absolute torsional modes were not identified, probably because lightly excited. The participation of a global mass equal to $85 \%$ requires the contribution of more than 100 modes since higher modes mainly involve local deformations along the structure.

At this step some numerical analyses have been carried out on the numerical model by means of linear time history analysis under the base excitation recorded during the earthquake occurred on 2012. Obtained results in terms of accelerations, both at the top of the dome and at the intermediate ring's level, are substantially comparable with the experimental values (see Figure 30 and Figure 31). As shown in the following figures, numerical and experimental accelerations have the same dominant frequency, and, during a few moments are almost overlapping with very close peak values.

A rough estimate of displacement at top of the structure has also been provided. At isolation level, displacement transducers didn't record any relative displacement between the dome and the columns. Since displacement measurements were not available along the height, acceleration signals recorded at the

Table 1. Results of modal analysis on FEM model.

\begin{tabular}{cccccccccc}
\hline Mode & Period & Frequency & \multicolumn{3}{c}{ Translational participating mass } & \multicolumn{2}{c}{ Rotational participating mass } & Modal deformation \\
\hline$[-]$ & {$[\mathrm{s}]$} & {$[\mathrm{Hz}]$} & $U X$ & $U Y$ & $U Z$ & $R X$ & $R Y$ & $R Z$ & {$[-]$} \\
\hline 1 & 0.36 & 2.8 & 0.37 & 0.09 & 0.00 & 0.11 & 0.46 & 0.00 & $1^{\circ}$ flexural in $x$ \\
2 & 0.36 & 2.8 & 0.07 & 0.31 & 0.00 & 0.38 & 0.09 & 0.08 & $1^{\circ}$ flexural in $y$ \\
3 & 0.34 & 3.0 & 0.02 & 0.06 & 0.00 & 0.09 & 0.03 & 0.48 & $1^{\circ}$ torsional \\
4 & 0.26 & 3.8 & 0.00 & 0.01 & 0.00 & 0.00 & 0.00 & 0.19 & $2^{\circ}$ torsional \\
5 & 0.24 & 4.1 & 0.02 & 0.05 & 0.00 & 0.02 & 0.01 & 0.01 & $2^{\circ}$ flexural in $y$ \\
\hline
\end{tabular}



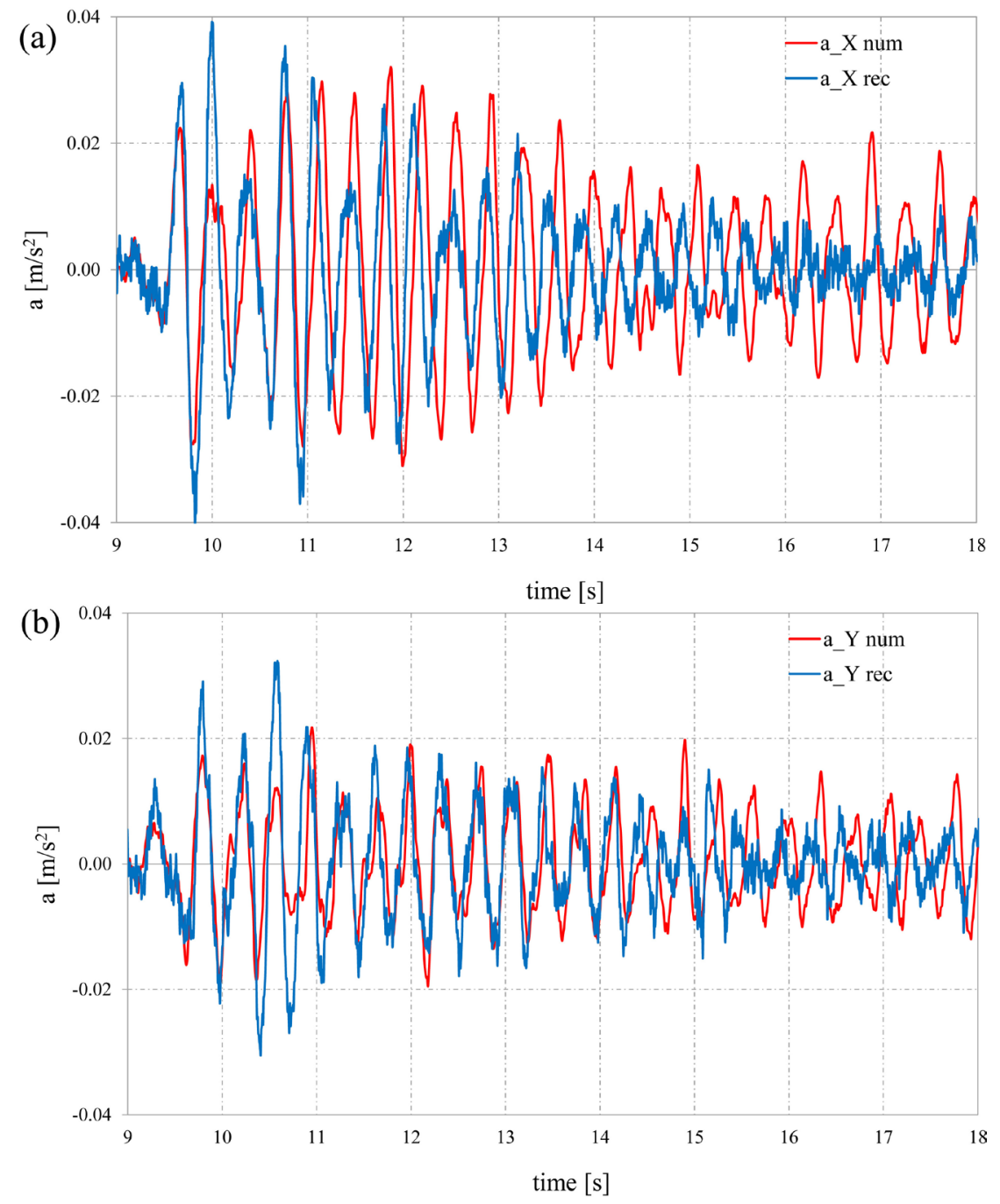

Figure 30. Comparison between recorded and numerical accelerations for a point at elevation $16.40 \mathrm{~m}$ in $X(\mathrm{a})$ and $Y(\mathrm{~b})$ direction.

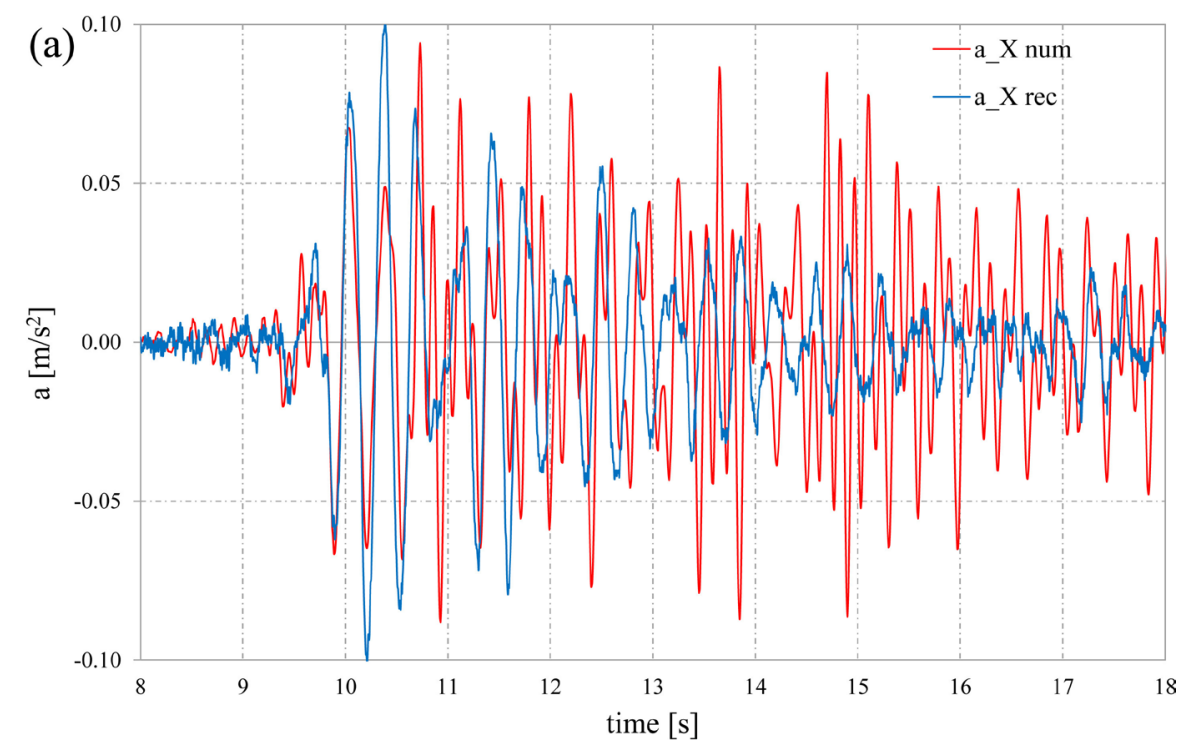




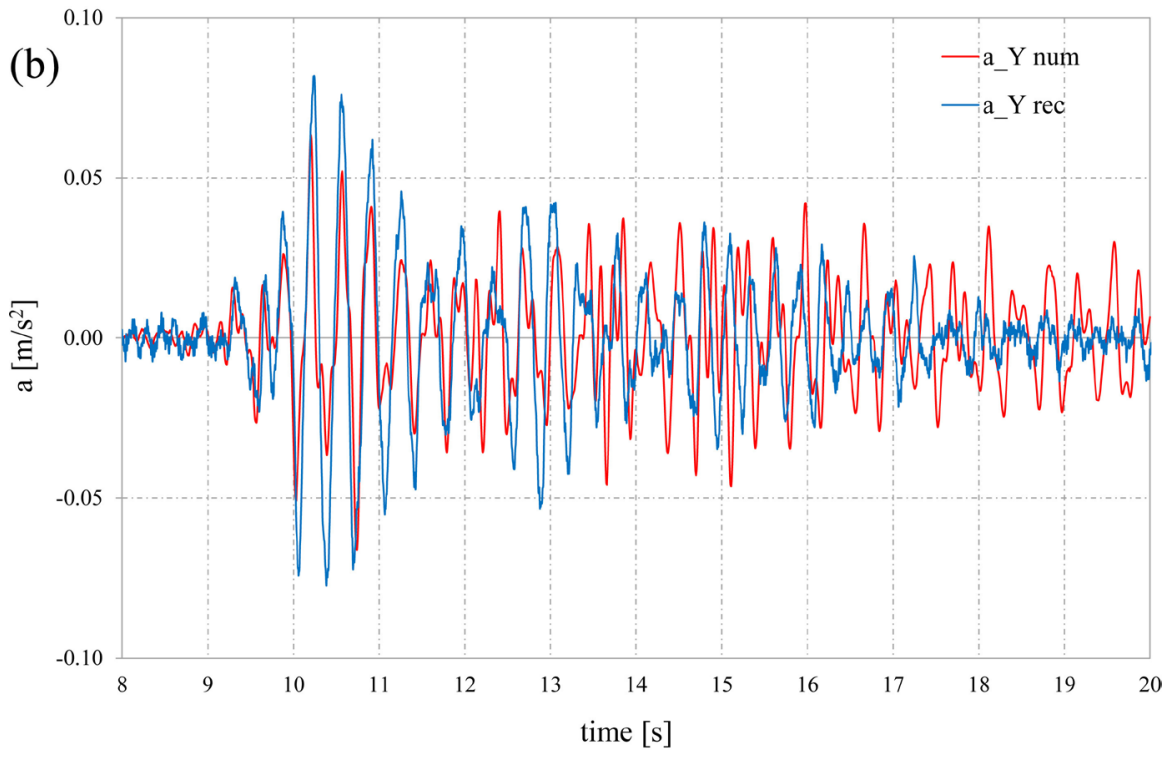

Figure 31. Comparison between recorded and numerical accelerations for a point at the top in $X(\mathrm{a})$ and $Y(\mathrm{~b})$ direction.

top have been processed in frequency domain: a $2^{\text {nd }}$ order high-pass filter, with a cutoff frequency of 0.75 and $1.25 \mathrm{~Hz}$, respectively, has been applied to velocity and displacement values, obtained by double integration. It was determined that the both computed displacement values and numerically found fall within the interval $\pm 0.2 \mathrm{~mm}$.

A satisfactory matching between the numerical and the experimental model was obtained, considering the problem arising from both the complex dynamic behaviour of the structure and the low level of assumed excitation with a remarkable effect of noise.

\subsection{Numerical Analysis under the Design Earthquake}

After calibrating the Sanctuary's FEM model, the structural behaviour under the action of the design earthquake has been investigated. According to Italian latest seismic provisions [23], the isolated structure has to be verified at Ultimate Limit State with an earthquake having $5 \%$ probability of exceedance during the reference life. The design spectrum has been defined assuming a nominal life of 50 years and a use class III (important structure) for a rock soil type (class A). Non-linear dynamic analyses have been carried out by assuming as seismic input seven couples of accelerograms compatible with the defined spectrum (Figure 32, Table 2), generated by the software REXEL v. 3.5 beta [24].

A first set of analysis has been performed on the complex numerical model by applying at the base two different scaled components of Irpinia earthquake (eq. \#287) simultaneously. Due to the complexity of the model and non-linear behaviour of the isolators, a high computational time was required by a direct integration time history analysis.

Figure 33 shows the hysteresis cycle of one of the 22 elasto-plastic dissipators 


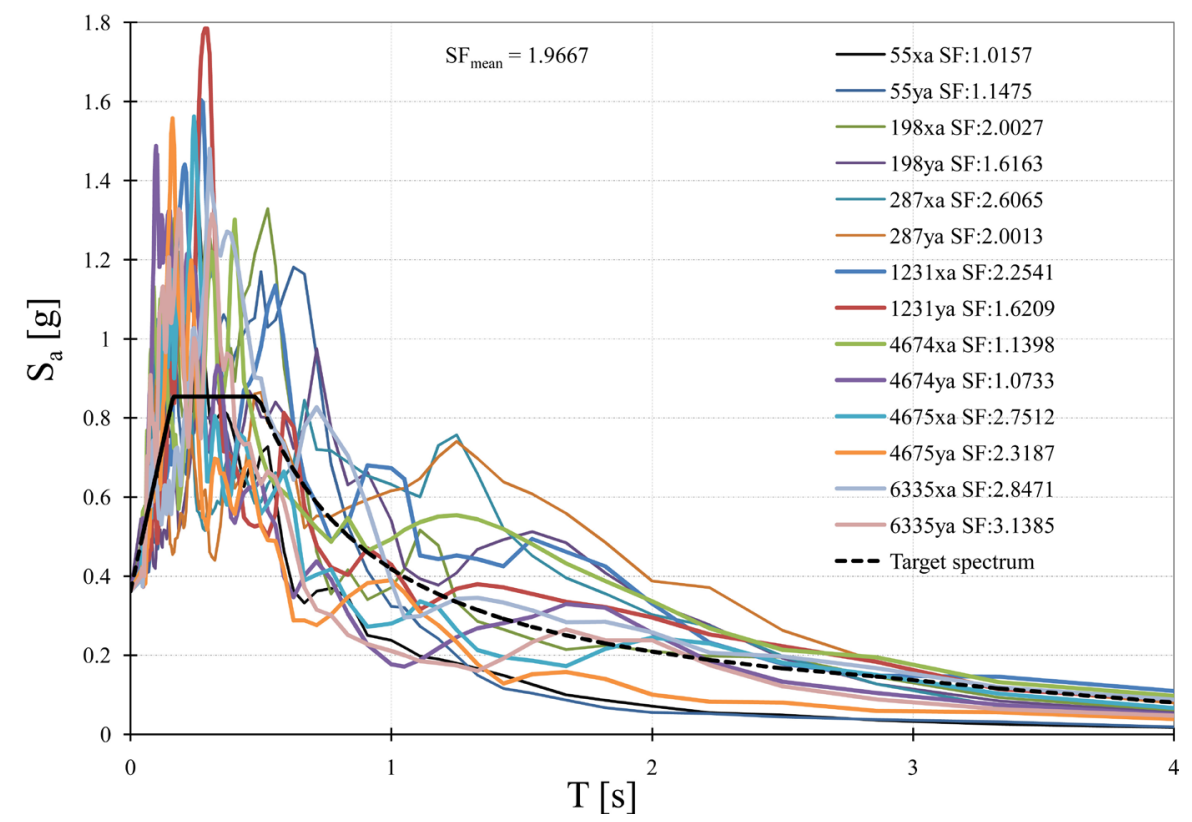

Figure 32. Spectra of the scaled accelerations records.

Table 2. Synthetic table of the 7 acceleration records.

\begin{tabular}{cccccccccc}
\hline Waveform ID & EQ ID & Station ID & EQ Name & Date & Mw & Fault Mech. & $\begin{array}{c}\text { Ep. Dist. } \\
{[\mathrm{km}]}\end{array}$ & $\begin{array}{c}\text { PGA_X } \\
{\left[\mathrm{m} / \mathrm{s}^{2}\right]}\end{array}$ & $\begin{array}{c}\text { PGA_Y } \\
{\left[\mathrm{m} / \mathrm{s}^{2}\right]}\end{array}$ \\
\hline 198 & 93 & ST64 & Montenegro & $15 / 04 / 1979$ & 6.9 & Thrust & 21 & 1.7743 & 2.1985 \\
6335 & 2142 & ST2557 & South Iceland (a.s.) & $21 / 06 / 2000$ & 6.4 & Strike slip & 15 & 1.2481 & 1.1322 \\
55 & 34 & ST20 & Friuli & $06 / 05 / 1976$ & 6.5 & Thrust & 23 & 3.4985 & 3.0968 \\
4674 & 1635 & ST2486 & South Iceland & $17 / 06 / 2000$ & 6.5 & Strike slip & 5 & 3.1176 & 3.3109 \\
4675 & 1635 & ST2487 & South Iceland & $17 / 06 / 2000$ & 6.5 & Strike slip & 13 & 1.2916 & 1.5325 \\
1231 & 472 & ST575 & Izmit & $17 / 08 / 1999$ & 7.6 & Strike slip & 9 & 1.5764 & 2.1922 \\
287 & 146 & ST93 & Campano Lucano & $23 / 11 / 1980$ & 6.9 & Normal & 23 & 1.3633 & 1.7756 \\
Mean & & & & & 6.8 & & 15.6 & 1.9814 & 2.1770 \\
\hline
\end{tabular}

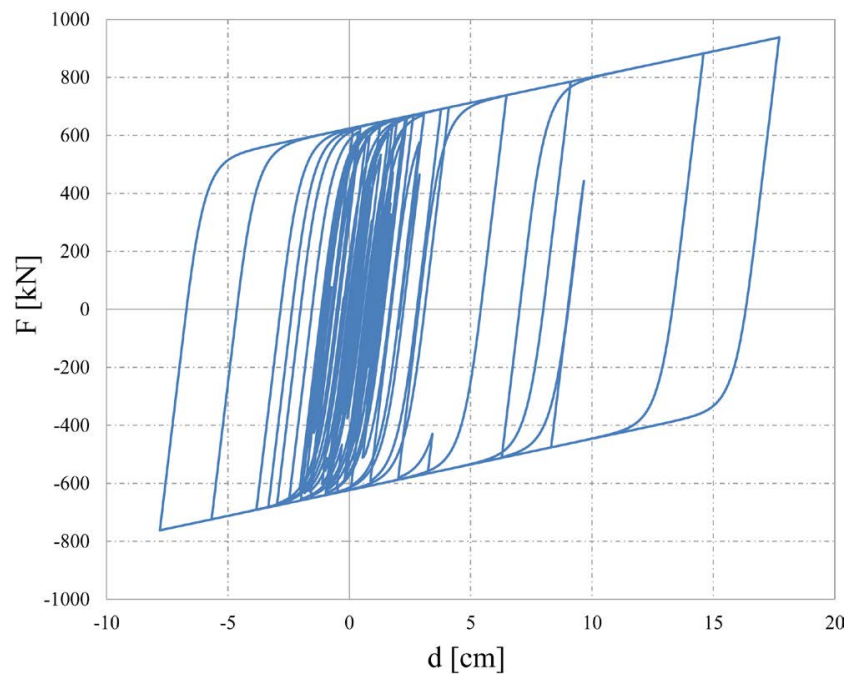

Figure 33. Hysteretical cycles of the dissipator at column 3. 
highlighting the strong excursion in the plastic field at the maximum displacement of the dome. A careful examination of the dome response demonstrated that it is characterized by an almost rigid body motion with a translation in the horizontal directions in the range of $20-25 \mathrm{~cm}$, while the displacements of the columns are much lower (Figure 34).

The maximum accelerations at top of the dome (Figure 35) vary in the range $\pm 2 \mathrm{~m} / \mathrm{s}^{2}$, while at the top of the columns, i.e. under the isolation system, they have peak values over $1 \mathrm{~g}$.

As the computational effort involved by the analysis was considerable and the dome substantially moved as a rigid body under the effect of design seismic

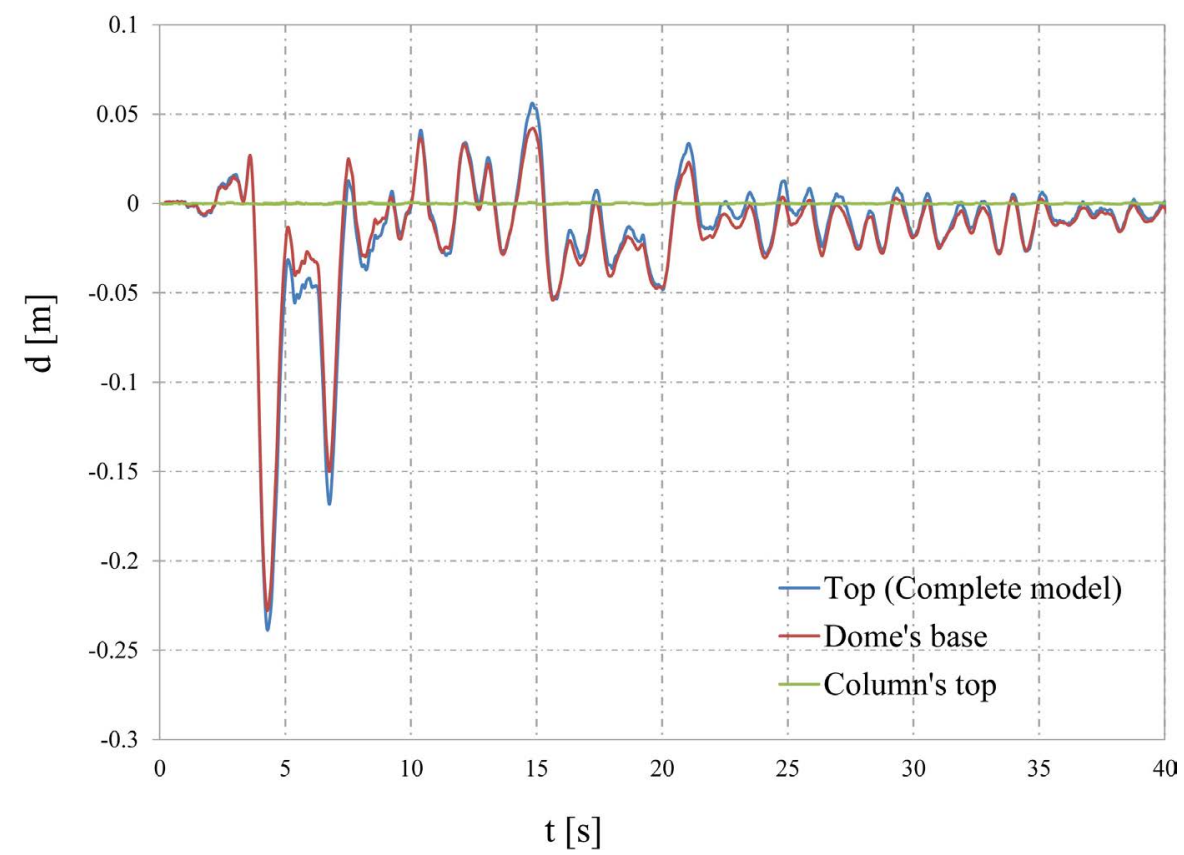

Figure 34. Displacements along $X$ in points at different elevations of the complete model.

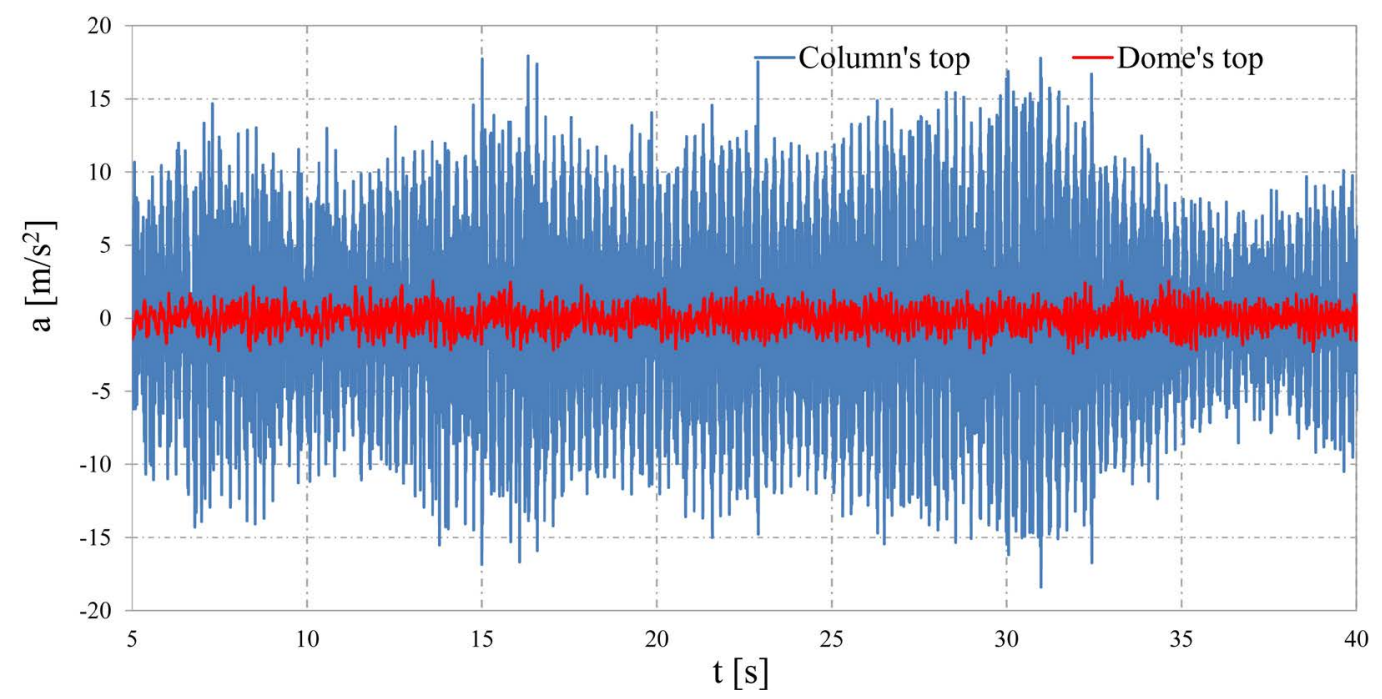

Figure 35. Accelerations along $X$ at the top of the structure (a) and of a column (b). 
action, the non-linear dynamic analyses relative to remaining six couples of compatible accelerograms have been performed on a simplified structural model. This model has been deduced from the complete one by replacing the dome with a master joint in the position of the center of mass having translational mass and inertia moment evaluated for the real structure. The accuracy of the simplified model was demonstrated under the same input of Irpinia earthquake: maximum displacement and time history of the master node are almost equal to the complete model (Figure 36) and their trend is satisfactorily matching.

When the structural response is known from at least 7 couples of accelerograms, the Italian Code allows (cfr. $\mathfrak{S}$ 7.3.5 NTC) to calculate the demand as the mean value of the most unfavourable effects obtained from the analyses (Table 3). The maximum isolators' displacements are shown for each analysis case.

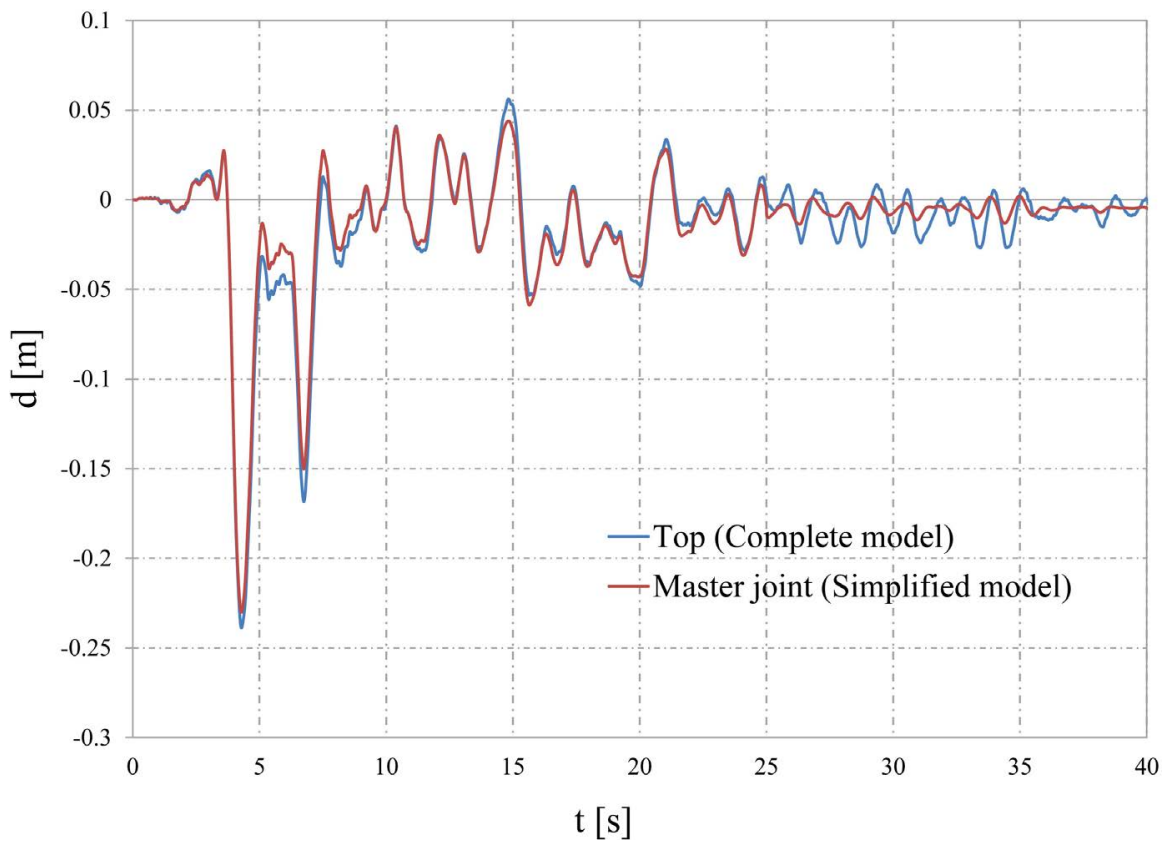

Figure 36. Comparison between the displacements along $X$ at the top of the complete model and those of the master node of the simplified model.

Table 3. Results of the 7 design analyses.

\begin{tabular}{cc}
\hline Earthquake & Max displacement $[\mathrm{cm}]$ \\
\hline Irpinia & 22 \\
Friuli & 5 \\
Montenegro & 17 \\
South Iceland 1 & 28 \\
South Iceland 2 & 10 \\
South Iceland AS & 21 \\
Izmit & 30 \\
Media & 19 \\
\hline
\end{tabular}


It is worth to point out that the isolated structure exhibits an isolation period of $T_{i s}=1.4 \mathrm{~s}$, and an equivalent damping $\xi_{e q}$ equal to $15 \%$ under the most severe earthquake (Izmit).

The results of the analyses demonstrated that, according to the actual regulations providing a PGA around $0.4 \mathrm{~g}$, the isolators, originally designed according to OPCM 3274 (2003) and OPCM 3431 (2005) for a PGA = 0.2 g, are not adequate, even if they were largely oversized at time of design. In tangential direction, the devices have a displacement demand of $19 \mathrm{~cm}$, higher than maximum capacity $( \pm 15 \mathrm{~cm})$, while in radial direction the displacement capacity can be deemed adequate $( \pm 20 \mathrm{~cm})$.

\section{Conclusions}

The proposed work proves the effectiveness and feasibility of the seismic isolation technology applied to an existent imposing and complex worship structure. The need of substituting the pre-existent bearings and the need to enhance the global seismic behaviour of the structure, led to design and install new seismic sliding bearings, made of elasto-plastic dissipative elements. The intervention consisted in rising the whole dome (whose mass is higher than 22,000 $t$ ) through the simultaneous operation of 114 hydraulic jacks, by allowing to reduce the seismic forces acting on the dome thus considerably reducing the internal stress at the base of the columns.

The isolation intervention involved a modification of the structural static scheme, by enabling the movements in tangential direction at the dome's base, while they were formerly blocked. Considering this, it was properly agreed to activate the monitoring system yet installed in the Sanctuary but not in operation. The new monitoring system includes an apparatus for the dynamic acquisition of 64 channels, the signal conditioners, a server continuously connected to Internet and a UPS device able to ensure the automatic shut-down and the re-start of the system during a black-out. The monitoring system's management is handed to properly designed software using three acquisition strategies ("threshold" for the dynamic/seismic monitoring, "periodic" to monitor the thermal and environmental variations, "continuous time" to acquire wind velocity and direction). The above system provides the remote access and the automatic transfer of data, particularly to the Italian Seismic Observatory of Structures (OSS) of the Department of Civil Protection (DPC).

Thanks to the analysis of the acquired data, it was possible to draw some important considerations on the structural behavior and to calibrate a complex FEM model. The latter has then been used to predict the response of the dome and the isolation system under the effect of the design earthquake.

\section{Acknowledgements}

The authors would like to thank the Italian firm FIP Industriale S.p.A. (Selvazzano Dentro-PD) for supplying the isolators and performing the daring inter- 
vention of dome's raising, substitution of the bearings and final lowering of the dome. The authors would also thank Boviar s.r.l. as well as INDAPRO s.r.l., which were the companies responsible of the upgrading and reactivation of the monitoring system of the "Our Lady of Tears Shrine" and of providing the new acquisition system and software, respectively. The system's management and maintenance was performed by the National Seismic Service of the Italian Department of Civil Protection within the network "Seismic Observatory of Structures", which is also gratefully acknowledged.

\section{Conflicts of Interest}

The authors declare no conflicts of interest regarding the publication of this paper.

\section{References}

[1] Kelly, J.M. (2004) Seismic Isolation. In: Bozorgnia, Y. and Bertero, V.V., Eds., Earthquake Engineering, from Engineering Seismology to Performance-Based Engineering, CRC Press, Boca Raton, 976 p. https://doi.org/10.1201/9780203486245.ch11

[2] Christopoulos, C., Filiatrault, A. and Bertero, V.V. (2006) Principles of Passive Supplemental Damping and Seismic Isolation. IUSS Press, Pavia, $480 \mathrm{p}$.

[3] Matsagar, V.A. and Jangid, R.S. (2008) Base Isolation for Seismic Retrofitting of Structures. Practice Periodical on Structural Design and Construction, 13, 175-185. https://doi.org/10.1061/(ASCE)1084-0680(2008)13:4(175)

[4] Mokha, A.S., Amin, N., Constantinou, M.C. and Zayas, V. (1996) Seismic Isolation Retrofit of Large Historic Building. Journal of Structural Engineering, 122, 298-308. https://doi.org/10.1061/(ASCE)0733-9445(1996)122:3(298)

[5] Petrini, L., Pinho, R. and Calvi, M.G. (2006) Criteri di progettazione antisismica degli edifici. IUSS Press, Pavia.

[6] Soong, T.T. and Spencer, B.F. (2002) Supplemental Energy Dissipation: State-of-the-Art and State-of-the-Practice. Engineering Structures, 24, 243-259. https://doi.org/10.1016/S0141-0296(01)00092-X

[7] Balageas, D. (2010) Structural Health Monitoring. John Wiley \& Sons, Hoboken.

[8] Farrar, C.R. and Worden, K. (2012) Structural Health Monitoring: A Machine Learning Perspective. John Wiley \& Sons, Hoboken. https://doi.org/10.1002/9781118443118

[9] Nicoletti, M., Lamonaca, B.G. and Spina, D. (2005) The Italian Network for Seismic Monitoring of Structures: Design, Present Level of Realisation and Further Development. Proceedings of the Sixth European Conference on Structural Dynamics (EURODYN2005), Paris, 4-7 September 2005, page.

[10] AITEC-Associazione Italiana Tecnico Economica Cemento (2006) The Sanctuary of the "Madonna delle Lacrime". Special Issue on Italian Concrete Structures for the 2nd fib Congress, Naples, May 2006, 350-353.

[11] Randazzo, F. (2001) The Sanctuary of the "Madonna delle Lacrime" in Syracuse, Italy. The Italian Industry of Cement, No. 5, May 2001, 394-415.

[12] Presidenza del Consiglio dei Ministri, Ordinanza No. 3274. Primi elementi in 
materia di criteri generali per la classificazione sismica del territorio nazionale e normative tecniche per le costruzioni in zona sismica, Roma, 20 Marzo 2003.

[13] Presidenza del Consiglio dei Ministri, Ordinanza No. 3431. Ulteriori modifiche ed integrazioni all'Ordinanza del PCM n. 3274 del 20.03.2003, Roma, 3 Maggio 2005.

[14] Serino G., Spizzuoco M., Marsico M. and Chandrasekaran S. (2008) Seismic Isolation and Modelling of a Worship Structure. Proceedings of Fourth European Conference on Structural Control, St. Petersburg, 8-12 September 2008, 711-718.

[15] Serino, G., Spizzuoco, M. and Marsico, M. (2006) Prove in Situ di carico e di scarico su appoggi antisismici di una copertura in c.a. Proceedings of Convegno Nazionale "Sperimentazione su materiali e strutture", Venezia.

[16] Serino, G., Spizzuoco, M. and Marsico, M. (2010) Application of Structural Isolation and Health Monitoring. The "Our Lady of Tears Shrine" in Syracuse (Italy). Structure \& Infrastructure Engineering, 6, 593-610. https://doi.org/10.1080/15732470903068763

[17] Spizzuoco, M., Serino, G. and Onorii, C. (2008) The Monitoring System of an Isolated Religious Building in Italy: A Recent Acquisition of the Italian "OSS". 4th European Conference on Structural Control, Vol. 2, St. Petersburg, 737-744.

[18] Losanno, D. (2009) Isolamento Sismico, Modellazione e Monitoraggio del "Santuario della Madonna delle Lacrime". Tesi di Laurea in Ingegneria Civile, Università degli studi di Napoli “Federico II". (In Italian)

[19] EERC (1994) Marquam Bridge-West Marquam Interchange: Testing of FIP Proprietary Seismic Isolation Hardware. Report No. EERCL/94-02, Earthquake Engineering Research Center, University of California, Berkeley.

[20] HITEC (1998) Technical Evaluation Report: Evaluation Findings for FIP-Energy Absorption Systems, L.C.C. Slider Bearings. CERF Report, HITEC 98-05.

[21] Ewins, D.J. (2000) Modal Testing: Theory, Practice and Application. Imperial College of Science, Technology and Medicine. Research Studies Press, London.

[22] International Federation for Structural Concrete fib. Model Code 2010.

[23] Ministero delle Infrastrutture. Decreto Ministeriale del 14 gennaio 2008, Norme tecniche per le costruzioni. (In Italian)

[24] Iervolino, I., Galasso, C. and Cosenza, E. (2010) REXEL: Computer Aided Record Selection for Code-Based Structural Analysis. Bulletin of Earthquake Engineering, 8, 339-362. https://doi.org/10.1007/s10518-009-9146-1 